Document downloaded from:

http://hdl.handle.net/10251/105473

This paper must be cited as:

Hassan, A.; Martinez-Ballester, S.; Gonzálvez-Maciá, J. (2017). A new moving boundary model for evaluating the performance of wet fins: Application to minichannel evaporators. Applied Thermal Engineering. 127:566-579. doi:10.1016/j.applthermaleng.2017.08.055

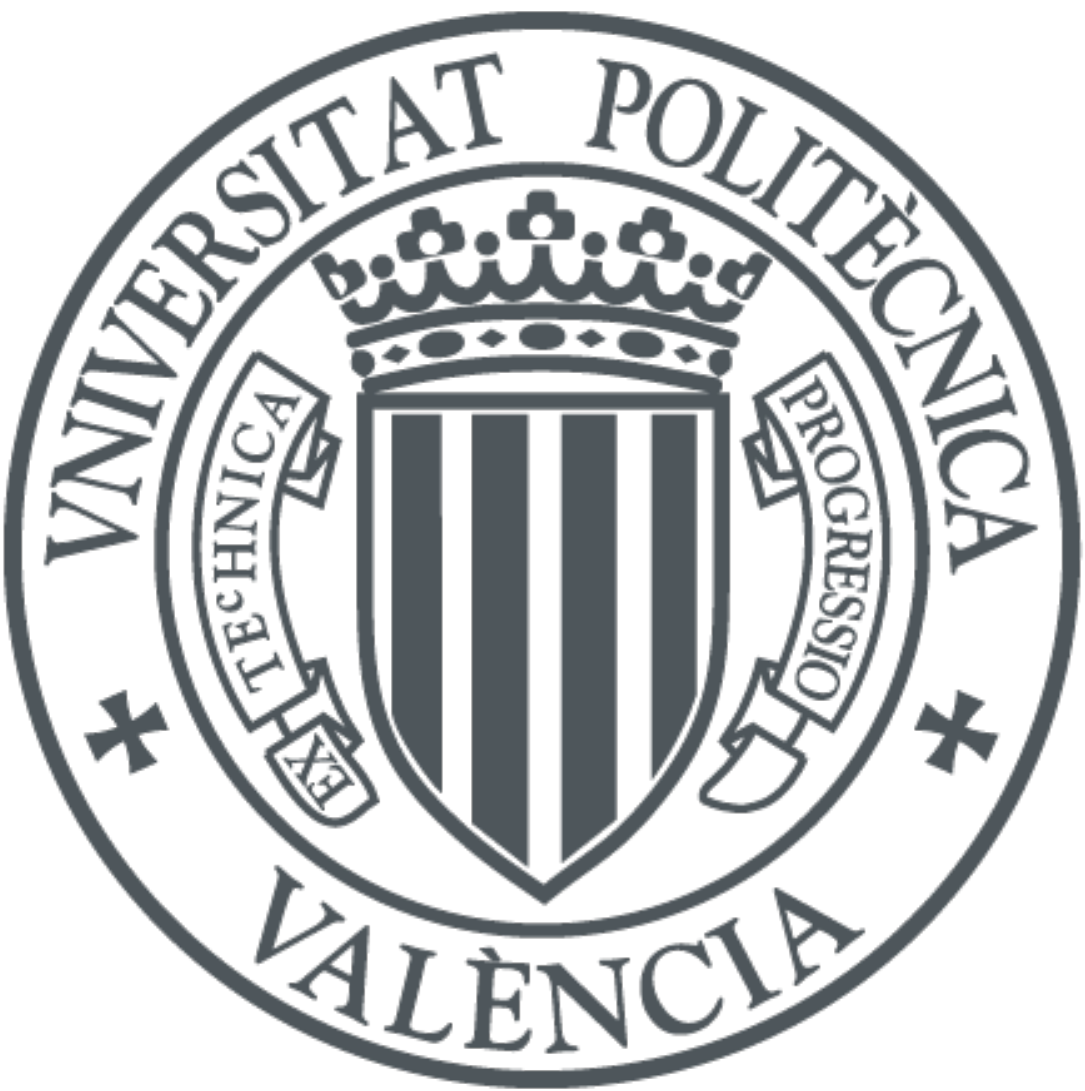

The final publication is available at

https://doi.org/10.1016/j.applthermaleng.2017.08.055

Copyright Elsevier

Additional Information 


\section{Accepted Manuscript}

Research Paper

\section{APPLIED}

THERMAL

ENGINEERING

A new moving boundary model for evaluating the performance of wet fins:

Application to minichannel evaporators

Abdelrahman Hussein Hassan, Santiago Martínez-Ballester, José Gonzálvez-

Maciá

PII:

S1359-4311(17)31616-2

DOI:

http://dx.doi.org/10.1016/j.applthermaleng.2017.08.055

Design · Processes - Equipment - Economics

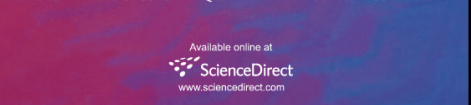

Reference:

ATE 10937

To appear in:

Applied Thermal Engineering

Received Date: $\quad 9$ March 2017

Revised Date: 28 June 2017

Accepted Date: $\quad 9$ August 2017

Please cite this article as: A. Hussein Hassan, S. Martínez-Ballester, J. Gonzálvez-Maciá, A new moving boundary model for evaluating the performance of wet fins: Application to minichannel evaporators, Applied Thermal Engineering (2017), doi: http://dx.doi.org/10.1016/j.applthermaleng.2017.08.055

This is a PDF file of an unedited manuscript that has been accepted for publication. As a service to our customers we are providing this early version of the manuscript. The manuscript will undergo copyediting, typesetting, and review of the resulting proof before it is published in its final form. Please note that during the production process errors may be discovered which could affect the content, and all legal disclaimers that apply to the journal pertain. 


\title{
A NEW MOVING BOUNDARY MODEL FOR EVALUATING THE PERFORMANCE OF WET FINS: APPLICATION TO MINICHANNEL EVAPORATORS
}

Abdelrahman Hussein Hassan ${ }^{\mathrm{a}, \mathrm{b}}$ *, Santiago Martínez-Ballester ${ }^{\mathrm{a}}$, José Gonzálvez-Maciáa

${ }^{a}$ Instituto Universitario de Investigación en Ingeniería Energética, Universitat Politècnica de València, Camino de Vera s/n, Valencia 46022, Spain.

${ }^{\mathrm{b}}$ Mechanical Power Engineering Department, Faculty of Engineering, Zagazig University, Zagazig 44519, Egypt.

* Corresponding Author. Tel: +34 963879127, Fax: +34 96389126,E-mail: abhusab1@ upvnet.upv.es

\begin{abstract}
In this paper, firstly, an innovative numerical model (Fin1D-MB) for wet fins of a minichannel evaporator was developed and verified. The proposed model is based on fin theory in conjunction with the moving boundary (MB) technique between wet and dry portions along the fin height. Secondly, a comparative study between the Fin1D-MB model and a comprehensive two-dimensional model (Fin2D-W) was implemented under different dehumidifying conditions. The results showed a good agreement between the two models in predicting the fin temperature profile and dehumidifying condition. However, the Fin1D-MB model saved computational cost by up to $95 \%$, compared to the Fin2D-W model. Nevertheless, the relative deviations in the air-side heat transfer rates should be taken into consideration, especially in the partially wet fin region. The main source of these deviations is the assumption of uniform air temperature and humidity ratio along the fin height used by the Fin1D-MB model.
\end{abstract}

KEYWORDS: wet fins, numerical modeling, minichannel evaporator, air-side analysis, heat and mass transfer. 


\section{NOMENCLATURE}

$\begin{array}{ll}A & \text { surface area }\left[\mathrm{m}^{2}\right] \\ a & \text { parameter defined in Eq. } 13\left[\mathrm{~kg}_{\mathrm{w}} \mathrm{kg}_{\mathrm{da}}{ }^{-1}\right] \\ A_{c} & \quad \text { cross-section area }\left[\mathrm{m}^{2}\right] \\ b & \text { slope of saturation curve } \\ & {\left[\mathrm{K}^{-1}\right]} \\ C & \text { McQuiston constant }\left[\mathrm{K}^{-1}\right] \\ C_{0} & \text { constant defined in Eq. } 2\left[\mathrm{~kg}_{\mathrm{w}} \mathrm{kg}_{\mathrm{da}}{ }^{-1}\right] \\ C_{p, m a} & \text { specific heat for moist air }\left[\mathrm{Jg}^{-1} \mathrm{~K}^{-1}\right] \\ \mathrm{G} & \text { mass flux }\left[\mathrm{kg} \mathrm{m} \mathrm{m}^{-1}\right] \\ H_{f} & \text { fin height [m] } \\ h_{f g} & \text { latent heat of water condensation }\left[\mathrm{J} \mathrm{kg}^{-1}\right] \\ k & \text { thermal conductivity }\left[\mathrm{W} \mathrm{m} \mathrm{K}^{-1}\right] \\ l & \text { distance between two wall cells }[\mathrm{m}]\end{array}$

\section{Greek symbols}

$\alpha \quad$ sensible heat transfer coefficient [W $\mathrm{m}^{-2} \mathrm{~K}^{-1}$ ]

$\alpha_{D} \quad$ mass transfer coefficient $\left[\mathrm{kg} \mathrm{m}^{-2} \mathrm{~s}^{-1}\right]$

$\alpha_{\text {wet }} \quad$ total heat transfer coefficient for wet case [W $\mathrm{m}^{-2} \mathrm{~K}^{-1}$ ]

$\beta \quad$ parameter defined in Eq. $2[\mathrm{~K}]$

$\varepsilon \quad$ thermal effectiveness [-

$\zeta_{1} \quad$ parameter defined in Eq. $22[\mathrm{~m}]$

$\zeta_{2} \quad$ parameter defined in Eq. $23[\mathrm{~m}]$

$\theta \quad$ temperature difference $[\mathrm{K}]$

$\lambda \quad$ thermal conductance $\left[\mathrm{W} \mathrm{K}^{-1}\right]$

$\psi \quad$ parameter defined in Eq. $2[\mathrm{~K}]$

$\omega$ humidity ratio difference $\left[\mathrm{kg}_{\mathrm{w}} \mathrm{kg}_{\mathrm{da}^{-1}}{ }^{-1}\right]$

\section{Subscripts}

a

air or air cell index

$m \quad$ dry fin parameter defined in Eq. $1\left[\mathrm{~m}^{-1}\right]$

$M \quad$ wet fin parameter defined in Eq. $2\left[\mathrm{~m}^{-1}\right]$

$\dot{m}$

mass flow rate $\left[\mathrm{kg} \mathrm{s}^{-1}\right]$

c

cond

centroid of tube wall cell

$n$ number of cells [-]

$\mathrm{N} \quad$ numerical grid dimension [-]

NMTU

number of mass transfer units [-]

NTU

$P$

number of transfer units [-]

conduction

$d p$

dew point

$f \quad$ fin or fin cell index

$f B \quad$ fin base

$\mathrm{fp} \quad$ fin portion index

$f T \quad$ fin tip

$Q \quad$ heat transfer rate [W]

RH relative humidity [\%]

SH superheat [K]

$T \quad$ temperature $\left[{ }^{\circ} \mathrm{C}\right]$

$T^{*} \quad$ modified temperature for moist air $\left[{ }^{\circ} \mathrm{C}\right]$

$U_{\text {wet }} \quad$ overall heat transfer coefficient for wet case $\left[\mathrm{W} \mathrm{m}{ }^{-2} \mathrm{~K}^{-1}\right.$ ]

$V \quad$ volume $\left[\mathrm{m}^{3}\right]$

$W \quad$ humidity ratio $\left[\mathrm{kg}_{\mathrm{w}} \mathrm{kg}_{\mathrm{da}}{ }^{-1}\right]$

$x, y, z \quad$ spatial coordinates [m] $k \quad$ direction index

lt lower tube

$r \quad$ refrigerant cell index

$s \quad$ surface of tube wall cell

sat saturated

seg tube segment

sens sensible

$t \quad$ tube or tube wall cell index

ut upper tube

$\mathrm{W}, \mathrm{E}, \quad$ directions of neighbor tube wall cell [-] $\mathrm{S}, \mathrm{N}$

\section{Superscripts}

in inlet

out outlet 


\section{INTRODUCTION}

Minichannel heat exchangers show great advantages over traditional fin-and-tube heat exchangers in compactness, effectiveness, and lower refrigerant charge, etc. Due to these advantages, traditional heat exchangers are now being replaced by the minichannel type in many air-conditioning and refrigeration applications.

When the minichannel heat exchanger is employed as an evaporator, some challenges emerge in the air-side such as the drainage of condensed water and frost formation. These challenges motivate the efforts to continue working in modeling of the simultaneous cooling and dehumidification process, even though considering the real phenomena in detail is really complicated for a robust and effective numerical model for minichannel evaporators.

Many minichannel evaporator models are available in the literature [1-5]. Most of these assume an adiabaticfin-tip at half the height (no accounting for tube-to-tube heat conduction) and uniform air properties along the fin height, and do not allow for partial dehumidification scenarios. These widely used modeling assumptions simplify the solution, but they result in less freedom to describe the actual processes.

Ren et al. [6] adopted an approximate analytical solution for their model that described the three-dimensional heat conductions via fins to allow for heat conduction between the minichannel evaporator tubes. They concluded that this approach significantly reduces computation time compared with the finite volume method and satisfactorily predicts heat conduction via the fins in minichannel heat exchangers. Their model does not allow for partial dehumidification scenarios. Furthermore, their validation process was conducted against a fully dry evaporator without dehumidification.

Huang et al. [7] proposed an air-to-fin heat and mass transfer minichannel evaporator model. This model accounts for variable geometry minichannel heat exchangers, partial dehumidification conditions, and tube-totube heat conduction. Their results showed that the average absolute capacity deviation between the predicted and measured values was approximately $3 \%$ for evaporators. Their model adopts the McQuiston's constant $C=$ $\left(W_{s a t, f B^{-}} W_{a}\right) /\left(T_{f B}-T_{a}\right)$ [8]. This approach simplifies the solution of the fin differential equation, but does not represent the actual physical behavior of the saturated humidity ratio on the psychrometric chart, as explained in [9-11].

Hassan et al. $[12,13]$ developed a comprehensive two-dimensional numerical model for the air-side analysis of minichannel evaporators, referred to as Fin2D-W, which operate under wet conditions. This model is based on 
the Fin2D model of Martínez-Ballester et al. [14], which divides the whole heat exchanger into number of segments along the refrigerant flow direction. Each segment is subdivided furthermore into different wall and fluid cells, to which the energy and mass balances are applied. The Fin2D-W model takes into account the 2D heat conduction in any wall element (either fin or tube), does not apply the analytical 1D fin solution, captures a detailed representation of air properties in both longitudinal and transverse directions, and finally allows for partial dehumidification scenarios. These authors compared the numerical results of the Fin2D-W model with the classical $\varepsilon$-NTU approach to assess the impact of the main classical modeling assumptions on the air-side performance of minichannel evaporators under different dehumidifying conditions and values of superheat. Three cases, which represent different inlet air conditions to the evaporator, and a range of tube temperatures were selected to capture different dehumidifying scenarios for the tube and fin. The main conclusions of their studies were as follows:

- The $\varepsilon$-NTU model was five time faster than the Fin2D-W model, for all the cases studied.

- If there is no dehumidification (dry fin), the main source of the deviations in results between the Fin2D-W and $\varepsilon$-NTU models is the assumption of uniform air temperature along the fin height.

- When dehumidification takes place, identifying the actual dehumidifying condition of the fin (totally or partially wet condition) has a more significant effect on the total heat transfer rate than the assumption of uniform air temperature and humidity ratio in the direction between tubes. In the partially wet fin region, the deviations in total heat transfer rate between the two models were up to 52\% [13].

- The $\varepsilon$-NTU model is not able to capture the precise dehumidifying condition of the fin, compared with the Fin2D-W model. It only considers three fin conditions, $0 \%, 50 \%$, and $100 \%$ dry fin. This is because of the discontinuity in the fin temperature profile, which is a consequence of adapting the adiabatic-fin-tip assumption. Besides this assumption, the high fin efficiency which usually exists in minichannel heat exchangers makes the estimation of the dehumidifying condition for the fin very sensitive to the tube temperature. This situation becomes more important in the presence of a temperature difference between adjacent tubes.

Based on the previous discussion, the first objective of the current work is to develop and verify a simpler numerical model, which is referred to as Fin1D-MB, compared to the Fin2D-W model. The proposed model is able to retain the most important heat and mass transfer phenomena as the Fin2D-W model does, but with a much lower computational cost like the $\varepsilon$-NTU approach. The second objective is to compare the air-side heat 
transfer results of the Fin1D-MB model with the Fin2D-W model in order to evaluate the sources of deviations between them.

\section{FIN1D-MB MODEL DEVELOPMENT}

The present model is based on the Fin2D-W model proposed by Hassan et al. [12, 13]. However, some new assumptions and techniques are considered, in order to reduce the complexity of the discretization scheme that subsequently results to less computation time. These can be summarized next:

- The studies of Martínez-Ballester et al. [14] and Asinari et al. [15] on minichannel condensers revealed that the transverse heat conduction (THC) in the fin along the air flow direction has a negligible effect on the predicted performance results. Moreover, several current fin surfaces have cuts in this direction (e.g. louvers, slits, etc.) which cancel the effect of THC. In the present model this effect is cancelled, which means no thermal connections between neighboring fin cells along the air flow direction.

- The main disadvantage of the Fin2D-W model is that it requires a detailed 2D discretization of the fin and air flow, which needs a long computation time, in order to obtain accurate temperature and humidity ratio profiles. This is the consequence of not applying the fin theory. In order to solve this issue in the current model, the fundamental fin theory (Eqs. 1 and 2) is adopted to obtain a one-dimensional temperature profile along the fin height. Accordingly, the fin is physically discretized in the direction of the air flow only.

- For totally dry fin (Bergman et al. [16], ch. 3, pp. 158-161):

Differential form: $\frac{d^{2} \theta_{a, f}}{d y^{2}}-m^{2} \theta_{a, f}=0,\left(T_{f B}\right.$ and $\left.T_{f T} \geq T_{d p}\right)$

General solution: $\theta_{a, f}(y)=C_{1} e^{m y}+C_{2} e^{-m y}$

where $m=\sqrt{\frac{P_{f} \cdot \alpha_{a, f}}{k_{f} \cdot A_{c, f}}}$, and $\theta_{a, f}=T_{a}-T_{f}$.

- For totally wet fin [10]:

Differential form: $\frac{d^{2} \theta_{a, f}}{d y^{2}}-M^{2} \theta_{a, f}=M^{2} \psi,\left(T_{f B}<T_{f T}<T_{d p}\right)$

General solution: $\theta_{a, f}(y)=C_{3} e^{M y}+C_{4} e^{-M y}-\psi$ 


$$
\begin{aligned}
& \text { where } M=m \sqrt{1+\beta b_{f}}, \beta=\frac{h_{f g}}{C_{p, m a} L e^{2 / 3}}, b_{f}=\frac{W_{\text {sat }, f T}-W_{\text {sat }, f B}}{T_{f T}-T_{f B}}, \psi=\frac{\beta C_{0}}{1+\beta b_{f}}, \\
& \text { and } C_{0}=W_{a}-\left[W_{\text {sat }, f B}-\left(b_{f} T_{f B}\right)\right]-b_{f} T_{a} .
\end{aligned}
$$

Eqs. $1 \mathrm{~b}$ and $2 \mathrm{~b}$ are the general solutions for the differential dry and wet fin equations (Eqs. 1a and 2a), respectively. These general solutions have to be coupled to get an expression which is capable of representing a continuous temperature profile for the whole fin under any dehumidifying condition. However, to identify whether the fin portion is dry or wet besides its size, a further discretization in the longitudinal direction is required according to the dehumidifying condition of the fin. It should be noted that Eqs. $1 b$ and $2 b$ do not imply the classical adiabatic-fin-tip assumption (in the cross-section at half the fin height), since boundary conditions have not yet been applied. An evaluation of the boundary conditions and constants $C_{1}, C_{2}, C_{3}$, and $C_{4}$ is given in Sub-subsection (2.2.2).

- Hassan et al. [12] and Martínez-Ballester et al. [14] concluded that the air temperature and humidity ratio profiles are quite flat along the direction between the tubes, excepting the air close to the tubes, which has obvious temperature and humidity ratio gradients. The portion of the fin which is occupied by the air close to the tubes is very small compared with the rest, approximately $1 / 30$ of the fin height. However, Martínez-Ballester et al. [17] developed a Fin1Dx3 model which takes into account this temperature gradient. Their model discretizes the fin into three pieces along the fin height, besides the discretization in the air flow direction. The fin pieces near the tubes always have the same height, which is referred to as "fin height ratio". This ratio is fixed and can be adjusted according to the fin geometry and operating conditions. Howeyer, this discretization scheme is incompatible with the proposed Fin1D-MB model. The Fin2D-W results revealed that the misprediction of the correct fin dehumidifying condition (totally dry, totally wet, or partially wet) predominates the air-side heat transfer deviations more than the assumption of uniform air temperature and humidity ratio between tubes. Furthermore, Martínez-Ballester et al. [18] implemented a comparative study between a detailed 2D gas cooler model and a simpler 1D model. In their 1D model, as in the current Fin1D-MB model, the fins were discretized only in the air flow direction and a uniform air temperature profile was assumed along the fin height. They found that the total deviation between the two models only reached a maximum of $2 \%$. Accordingly, in the current work the effect of non-mixed air between tubes is neglected, and the fin is virtually discretized in the longitudinal direction according to the dehumidifying condition of the fin, as mentioned in the previous point.

\subsection{Evaporator Discretization}


Each evaporator tube is discretized along the $x$-direction (refrigerant flow direction) to $\mathrm{N}_{\text {seg }}$ segments, as shown in Fig. 1a.

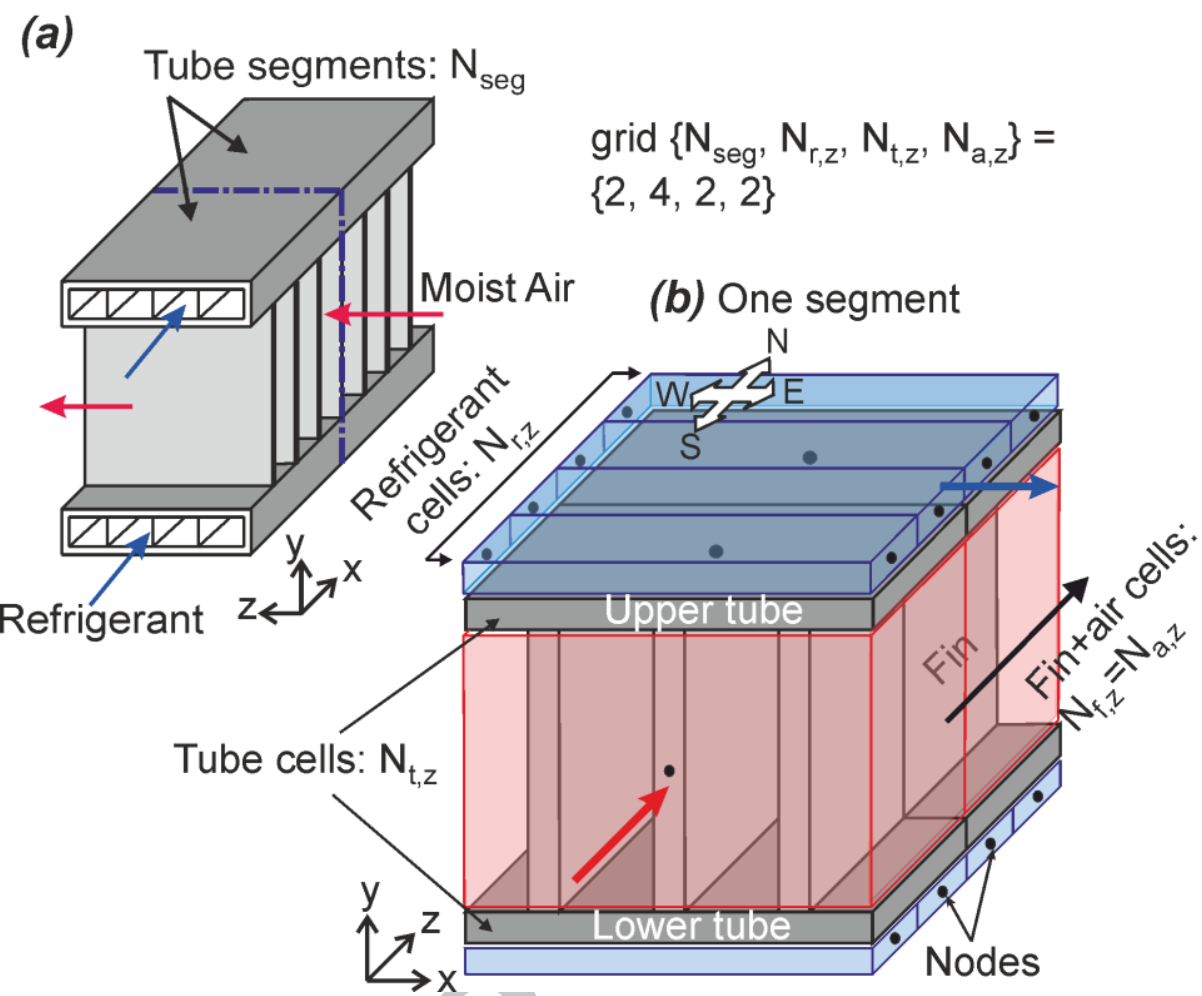

Fig. 1 - (a) Discretization of evaporator tubes into segments. (b) Schematic representation of a segment discretization into cells.

Each segment (Fig. 1b) consists of: a refrigerant flow that is split into $\mathrm{N}_{\mathrm{r}, \mathrm{z}}$ channels in the $z$-direction (air flow direction); upper and lower flat tubes which are discretized into $\mathrm{N}_{\mathrm{t}, \mathrm{z}}$ cells in the $\mathrm{z}$-direction; air flow and fins which are discretized into the same number of cells in the $z$-direction, where $\mathrm{N}_{\mathrm{a}, \mathrm{z}}=\mathrm{N}_{\mathrm{f}, \mathrm{z}}$. Also, to obtain a more consistent solution, $\mathrm{N}_{\mathrm{t}, \mathrm{Z}}$ is always assumed to be equal to $\mathrm{N}_{\mathrm{a}, \mathrm{z}}$ in the current work. The discretization for an evaporator is summarized in the following as a grid: $\left\{\mathrm{N}_{\mathrm{seg},} \mathrm{N}_{\mathrm{r}, \mathrm{z}}, \mathrm{N}_{\mathrm{t}, \mathrm{z}}, \mathrm{N}_{\mathrm{a}, \mathrm{z}}\right\}$. For illustration of the nomenclature, the numerical example shown in Fig. 1 corresponds to a grid: $\{2,4,2,2\}$.

\subsection{Governing Equations}

Every fluid cell (either refrigerant or air) has two nodes, which correspond to the inlet and outlet sections in the fluid flow direction. The tube wall cells have only one node located in the centroid of the cell, as shown in Fig. 1b. It can be seen that the fin does not have any nodes because a continuous function governs in this case. The same assumptions which were used in the development of Fin2D-W model ([13], Section 2) have also been applied in the current model. However, as mentioned earlier, the main difference between the two models is that the Fin1D-MB model assumes uniform air properties along the fin height, unlike the Fin2D-W model. 
The analysis of refrigerant-side for the current model was already done by Martínez-Ballester et al. [17], so this paper only focuses on the air-side analysis of minichannel evaporators. As the current work only focuses on the thermal performance, the pressure losses are assumed to be zero. Under this situation, the governing equations can be expressed as follows.

\subsubsection{Tube wall analysis}

The energy conservation equation within any tube wall cell $t$ in contact with $n_{a}$ air cells, and $n_{f}$ fin cells can be written as:

$\nabla\left(k_{t} \cdot \nabla T_{c, t}\right) d V+\sum_{a=1}^{n_{a}} U_{\mathrm{wet}, a, t}\left(T_{a, t}^{*}-T_{c, t}\right) d A_{a, t}+\sum_{f=1}^{n_{f}}-\left.d Q_{\text {cond }, f}\right|_{\text {fin root }}=0$

It is important to mention that a linearization scheme, which was proposed by Elmahdy and Biggs [9], is used in

Eq. 3 to relate the saturated air humidity ratio $W_{\text {sat, } t}$ to its corresponding surface tube wall temperature $T_{s, t}$, where $W_{\mathrm{sat}, s, t}=a_{a, t}+b_{a, t} \cdot T_{s, t}$

$T_{c, t}$ is the temperature evaluated at the centroid of the tube wall cell $t$. Additionally,

$U_{\text {wet }, a, t}=1 /\left[\left(1 / \alpha_{\text {wet }, a, t}\right)+\left(t_{t} / 2 k_{t}\right)\right]$

$\alpha_{\mathrm{wet}, a, t}=\alpha_{a, t}\left(1+\beta b_{a, t}\right)$

$b_{a, t}=\left(W_{a}-W_{\text {sat }, s, t}\right) /\left(T_{d p}-T_{s, t}\right)$

$T_{a, t}^{*}=\frac{T_{a}+\beta\left[W_{a}-\left(W_{\mathrm{sat}, s, t}-b_{a, t} T_{s, t}\right)\right]}{1+\beta b_{a, t}}$ is the overall heat transfer coefficient for the wet case, which considers the total convection and conduction (within a half thickness of the tube wall cell) heat resistances;

is the total heat transfer coefficient for wet case, which considers the sensible and latent convection heat transfer, if there is no dehumidification then $\alpha_{\text {wet }, a}=\alpha_{a}$;

is the slope of saturation curve, which is evaluated between the dew point of surrounding air and tube surface temperature; and

is the modified temperature for moist air, if there is no dehumidification then $T_{a, t}^{*}=T_{a}$.

The first term in Eq. 3 represents the 2D heat conduction between the current tube wall cell and neighboring

tube wall cells in $x-z$ plane. The second terms represents the total heat transfer between the current tube wall cell and adjacent moist air cells. While, the last term represents the total heat conducted from/to the fin cells in contact with the tube.

\subsubsection{Fin analysis}

The physical discretization of the fin is 1D (along the air flow direction). However, to capture the actual fin condition, it has to be virtually discretized into three portions (fp1, fp2, and fp3) along its height ( $y$-direction), as it can be seen in Fig. 2a. Each section has its independent local coordinates and temperature function. The lower 
(fp1) and upper (fp3) portions are always assumed to be fully wet, while the middle one (fp2) is always assumed to be fully dry.

\section{(a)}

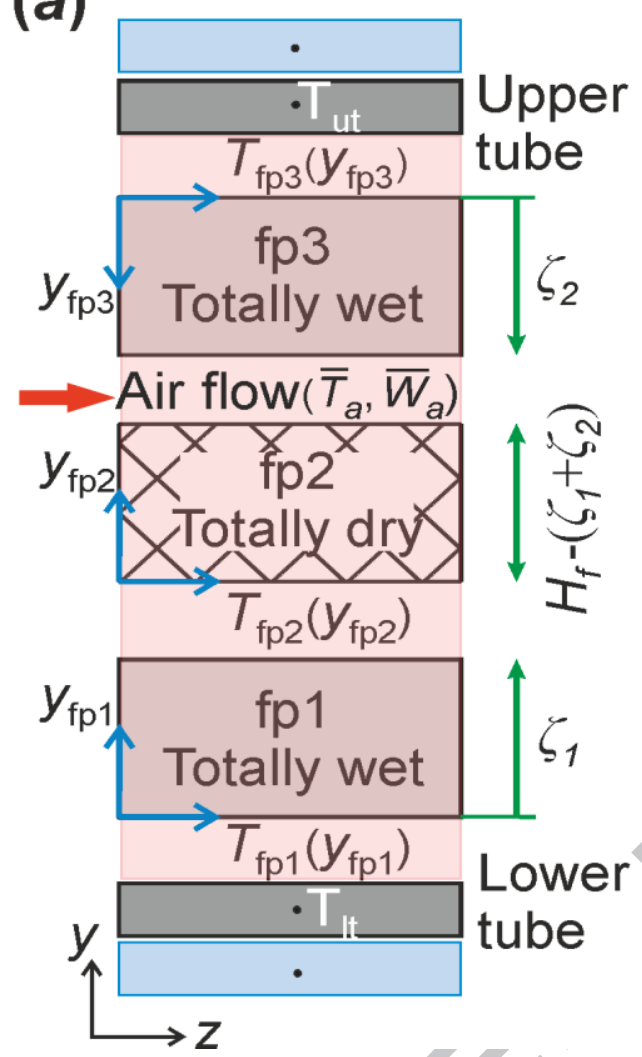

(b)

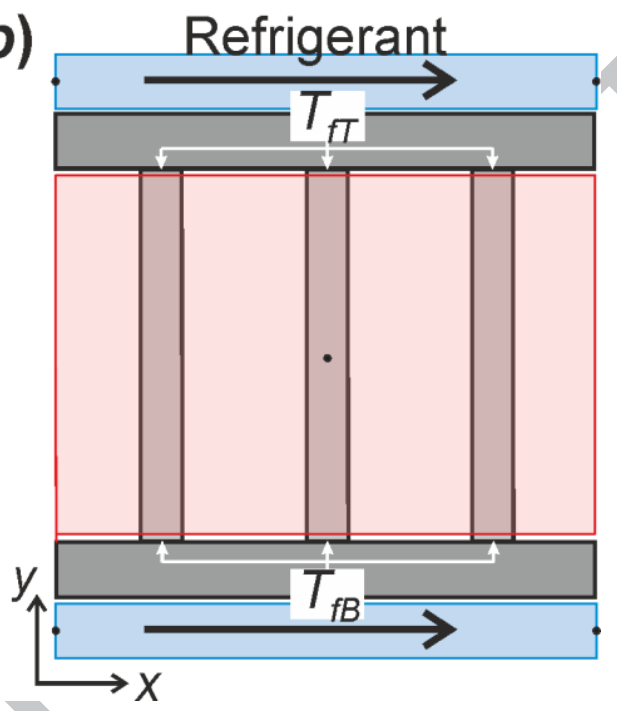

Fig. $2-$ (a) $y-z$ plane, which shows the virtual discretization of the fin in $y$-direction and boundaries between wet and dry portions, $\zeta_{1}$ and $\zeta_{2}$ (b) $y$-x plane, which shows the location of $T_{f B}$ and $T_{f T}$.

The area of each portion is specified according to $\zeta_{1}$ (measured from the fin base) and $\zeta_{2}$ (measured from the fin tip) which represent the boundaries between the wet and dry portions. These boundaries are movable from one fin cell to another according to $T_{f T}, T_{f B}$, and $T_{d p}$. Consequently, the fin could be totally wet $\left(\zeta_{1}=H_{f}\right.$ and $\left.\zeta_{2}=0\right)$, totally dry $\left(\zeta_{1}=\zeta_{2}=0\right)$, or partially wet $\left(H_{f}>\zeta_{1,2} \geq 0\right)$. This is the reason for the model's name: "Fin1D" because it applies a one-dimensional equation for each fin/air connection and "MB" because it adopts the moving boundary technique to identify the wet and dry portions of the fin.

Therefore, each fin cell has a composed governing equation (Eq. 4) which consists of three sub-functions that present a continuous temperature profile for the entire fin under any dehumidifying condition.

$\theta_{a, f}(y) \begin{cases}\theta_{a, \mathrm{fp} 1}\left(y_{\mathrm{fp} 1}\right)=C_{1} e^{M \cdot y_{\mathrm{fp} 1}}+C_{2} e^{-M \cdot y_{\mathrm{fp} 1}}-\psi & 0 \leq y_{\mathrm{fp} 1} \leq \zeta_{1} \\ \theta_{a, \mathrm{fp} 2}\left(y_{\mathrm{fp} 2}\right)=C_{3} e^{m \cdot y_{\mathrm{fp} 2}}+C_{4} e^{-m \cdot y_{\mathrm{fp} 2}} & 0 \leq y_{\mathrm{fp} 2} \leq H_{f}-\left(\zeta_{1}+\zeta_{2}\right) \\ \theta_{a, \mathrm{fp} 3}\left(y_{\mathrm{fp} 3}\right)=C_{5} e^{M \cdot y_{\mathrm{fp} 3}}+C_{6} e^{-M \cdot y_{\mathrm{fp} 3}}-\psi & 0 \leq y_{\mathrm{fp} 3} \leq \zeta_{2}\end{cases}$ 
where $H_{f}$ is the total fin height. The unknown constants from $C_{l}$ to $C_{6}$ must be evaluated from the boundary conditions of the heat transfer problem along the fin height. Therefore, the conditions required to evaluate these constants are:

B.C. $\left\{\begin{array}{l}\theta_{a, \mathrm{fp} 1}\left(y_{\mathrm{fp} 1}=0\right)=\theta_{a, f B}=T_{a}-T_{f B}, \\ \theta_{a, \mathrm{fp} 1}\left(y_{\mathrm{fp} 1}=\zeta_{1}\right)=\theta_{a, \mathrm{fp} 2}\left(y_{\mathrm{fp} 2}=0\right), \\ \left.\frac{d \theta_{a, \mathrm{fp} 1}}{d y_{\mathrm{fp} 1}}\right|_{y_{\mathrm{fp} 1}=\zeta_{1}}=\left.\frac{d \theta_{a, \mathrm{fp} 2}}{d y_{\mathrm{fp} 2}}\right|_{y_{\mathrm{fp} 2}=0}, \\ \theta_{a, \mathrm{fp} 3}\left(y_{\mathrm{fp} 3}=0\right)=\theta_{a, f T}=T_{a}-T_{f T}, \\ \left.\left.\frac{d \theta_{a, \mathrm{fp} 2}}{d y_{\mathrm{fp} 2}}\right|_{y_{\mathrm{fp} 2}=H_{f}-\left(\zeta_{1}+\zeta_{2}\right)}=-\left.\frac{d \theta_{a, \mathrm{fp} 3}}{d y_{\mathrm{fp} 3}}\right|_{y_{\mathrm{fp} 3}=\zeta_{2}},\left(\zeta_{1}+\zeta_{2}\right)\right)=\theta_{a, \mathrm{fp} 3}\left(y_{\mathrm{fp} 3}=\zeta_{2}\right), \text { and } \\ \text { the negative sign in the right-hand-side comes from the opposite directions of } y_{\mathrm{fp} 2} \text { and } y_{\mathrm{fp} 3} .\end{array}\right.$

Eq. 4 and its boundary conditions (Eq. 5) assume uniform air temperature and humidity ratio along $y$-direction within the air cell in contact with the evaluated fin cell. So, $\bar{T}_{a}$ and $\bar{W}_{a}$ represent the integrated mean values for air temperature and humidity ratio within the cell, respectively. The locations of $T_{f B}$ and $T_{f T}$ are illustrated in Fig. 2b. In this way, it is possible to solve analytically Eq. 4 to know the fin temperature profile $T_{f}$ as follows:

$T_{f}(y)=\left\{\begin{array}{l}T_{\mathrm{fp} 1}\left(y_{\mathrm{fp} 1}\right)=\bar{T}_{a}-\theta_{a, \mathrm{fp} 1}\left(y_{\mathrm{fp} 1}\right) \\ T_{\mathrm{fp} 2}\left(y_{\mathrm{fp} 2}\right)=\bar{T}_{a}-\theta_{a, \mathrm{fp} 2}\left(y_{\mathrm{fp} 2}\right) \\ T_{\mathrm{fp} 3}\left(y_{\mathrm{fp} 3}\right)=\bar{T}_{a}-\theta_{a, \mathrm{fp} 3}\left(y_{\mathrm{fp} 3}\right)\end{array}\right\}_{f}=\left[\mathrm{A}\left(y_{\mathrm{fp} 1}, y_{\mathrm{fp} 2}, y_{\mathrm{fp} 3}\right)\right] \cdot\left[\begin{array}{l}\bar{T}_{a} \\ T_{f B} \\ T_{f T} \\ \bar{\psi}\end{array}\right]$

$A\left(y_{f p 1}, y_{f p 2}, y_{f p 3}\right)$ is a $3 \times 4$ matrix that depends on the local coordinates, fin geometry, dry fin parameter $m$, wet fin parameter $M, \zeta_{1}$, and $\zeta_{2}$

\subsubsection{Moist air analysis}

Eq. 7 shows the heat balance within an air cell $a$ in contact with a fin cell $f$, which is discretized into three portions $(\mathrm{fp}=1-3)$, and $n_{t}$ tube wall cells $\left(t=1-n_{t}\right)$.

$\dot{m}_{a} \cdot C_{p, m a} \cdot d T_{a}=-d Q_{\mathrm{sens}, a, f}-\sum_{t=1}^{n_{t}} \alpha_{a, t}\left(T_{a}-T_{s, t}\right) d A_{a, t}$

$Q_{\text {sens, } a, f}$ is the sensible heat transferred to the adjacent fin cell $f$, which can be expressed as: 
$d Q_{\mathrm{sens}, a, f}=\sum_{\mathrm{fp}=1}^{3} \alpha_{a, \mathrm{fp}} \cdot \theta_{a, \mathrm{fp}} \cdot d z d y_{\mathrm{fp}}$

The mass balance within any air cell is

$\dot{m}_{a} \cdot d W_{a}=-d \dot{m}_{\mathrm{water}, a, f}-\sum_{t=1}^{n_{t}} \alpha_{D_{a, t}}\left(W_{a}-W_{\mathrm{sat}, s, t}\right) d A_{a, t}$

$\dot{m}_{\text {water }, a f f}$ is the mass flow rate of condensed water to the adjacent fin cell $f$, which is calculated as:

$d \dot{m}_{\mathrm{water}, a, f}=\sum_{\mathrm{fp}=1}^{3} \alpha_{D_{a, \mathrm{fp}}} \cdot \omega_{a, \mathrm{fp}} \cdot d z d y_{\mathrm{fp}}$

where

$\alpha_{D}=\frac{\alpha_{a}}{L e^{2 / 3} \cdot C_{p, m a}}$

is the mass transfer coefficient for air-side which based on Chilton-Colburn analogy (Kuehn et al. [19], ch. 11, pp. 309-311); and

$\omega_{a, \mathrm{fp}}=W_{a}-W_{\text {sat,fp }}\left\{T_{\mathrm{fp}}\left(y_{\mathrm{fp}}\right)\right\} \begin{aligned} & \text { is the humidity ratio difference between the surrounding air and saturated air } \\ & \text { evaluated at specific fin portion temperature. }\end{aligned}$ In Eq. 9 the air cell can only exchange the mass with the tube wall cells and fin portions whose temperatures are below the dew point of the air (dehumidification process exists). If any of these is above or equal to the dew point of air, it is not considered by the mass balance.

\subsection{Numerical Scheme}

The finite volume method is applied to discretize the governing equations described in the previous subsection. However, it is necessary to assume temperature and humidity ratio profiles for the moist air in order to obtain the estimation of the integral of the heat and mass transfer between the air and corresponding piece of wall (Eq.

3 ) in the fluid flow direction. This integration must be consistent with the integration of the coincident terms in Eqs. 7 and 9. Accordingly, the linear fluid temperature variation (LFTV) scheme was employed, as Corberán et al. [20] suggested for this type of applications. After discretizing the Laplacian term in Eq. 3 using the classical finite difference approach, besides applying the LFTV scheme; Eq. 3 can be now expressed as follows:

$\lambda_{t} \cdot T_{c, t}-\sum_{k=\mathrm{W}, \mathrm{E}, \mathrm{S}, \mathrm{N}} \lambda_{t-k} \cdot T_{c, k}=\sum_{a=1}^{n_{a}} U_{\mathrm{wet}, a, t}\left(\bar{T}_{a, t}^{*}-T_{c, t}\right) P_{a, t} \cdot \Delta z_{a, t}+\left.\sum_{f=1}^{n_{f}} Q_{\text {cond }, f}\right|_{\text {fin root }}$

where 
$\bar{T}_{a, t}^{*}=\frac{\left.T_{a, t}^{*}\right|^{\text {in }}+\left.T_{a, t}^{*}\right|^{\text {out }}}{2}, \lambda_{t-\mathrm{W}}=\frac{k_{t} A_{t-\mathrm{W}}}{\delta l_{t-\mathrm{W}}}, \lambda_{t-\mathrm{E}}=\frac{k_{t} A_{t-\mathrm{E}}}{\delta l_{t-\mathrm{E}}}, \lambda_{t-\mathrm{S}}=\frac{k_{t} A_{t-\mathrm{S}}}{\delta l_{t-\mathrm{S}}}, \lambda_{t-\mathrm{N}}=\frac{k_{t} A_{t-\mathrm{N}}}{\delta l_{t-\mathrm{N}}}$, and $\lambda_{t}=\sum_{k=\mathrm{W}, \mathrm{E}, \mathrm{S}, \mathrm{N}} \lambda_{t-k}$.

All $\lambda_{t-k}$ terms refer to the conductance between the current tube wall cell $t$ and the adjacent tube wall cell in the $k$-direction. The directions reference used in the current model is shown in Fig. $1 b$.

To obtain the outgoing temperature and humidity ratio of the air, Eqs. 7 and 9 have to be solved; however, the integration of Eqs. 8 and 10 must be done previously. The total sensible heat transfer along the fin cell can be expressed as:

$\int d Q_{\mathrm{sens}, a, f}=\int \sum_{\mathrm{fp}=1}^{3} \alpha_{a, \mathrm{fp}} \cdot \theta_{a, \mathrm{fp}} \cdot d z d y_{\mathrm{fp}}=\sum_{\mathrm{fp}=1}^{3} \alpha_{a, \mathrm{fp}} \cdot A_{a, \mathrm{fp}} \cdot \bar{\theta}_{a, \mathrm{fp}}$

where $\bar{\theta}_{a, \mathrm{fp}}$ is the integrated mean value of $\theta_{a, \mathrm{fp}}\left(y_{\mathrm{fp}}\right)$ for each fin portion.

While, the total mass transferred to the fin surface is given by:

$\int d \dot{m}_{\mathrm{water}, a, f}=\int \sum_{\mathrm{fp}=1}^{3} \alpha_{D_{a, \mathrm{fp}}} \cdot \omega_{a, \mathrm{fp}} \cdot d z d y_{\mathrm{fp}}=\sum_{\mathrm{fp}=1}^{3} \alpha_{D_{a, \mathrm{fp}}} \cdot A_{a, \mathrm{fp}} \cdot \bar{\omega}_{a, \mathrm{fp}}$

where $\bar{\omega}_{a, \mathrm{fp}}=\bar{W}_{a}-a_{a, f}-b_{a, f}\left(\bar{T}_{a}-\bar{\theta}_{a, \mathrm{fp}}\right), \bar{W}_{a}=\frac{W_{a}^{\mathrm{in}}+W_{a}^{\mathrm{out}}}{2}, \bar{T}_{a}=\frac{T_{a}^{\mathrm{in}}+T_{a}^{\mathrm{out}}}{2}$

$a_{a, f}$ and $b_{a, f}$ are parameters which resulted from the linearization process of saturation curve, where $W_{\text {sat } f}(y)=a_{a, f}$ $+b_{a, f} \cdot T_{f}(y)[10,11]$. These parameters are evaluated between the average dew point of surrounding air and the minimum fin root temperature (either the fin base or tip), as it is illustrated in Fig 3.

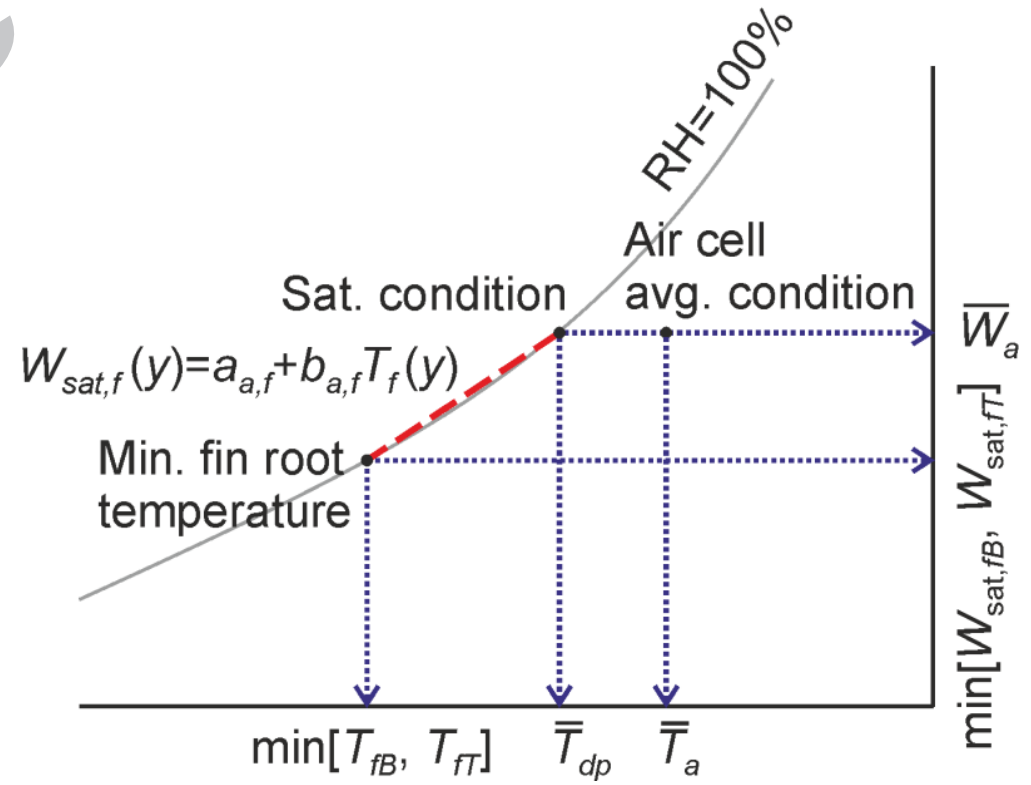


Fig. 3 - Linearization scheme of saturation curve used in the Fin1D-MB model for wet fin analysis.

The novelty of the current model is the implementation of integration of the fin temperature function. This integration takes into account the effect of different dehumidifying conditions on the fin temperature profile, and heat conduction between tubes through the fin. Instead of using the current approach, other evaporator models in literature assume adiabatic section at half the fin height; then the adiabatic-fin-tip efficiency, for totally dry or wet condition, is applied. However, some models, which use the adiabatic-fin-tip efficiency, tried to apply more or less artificial approaches in order to include heat conduction between tubes [21].

Substituting Eqs. 12 and 13 into Eqs. 7 and 9, respectively. The total sensible heat transfer from the air cell to the corresponding fin and tube wall cells is expressed as follows:

$\dot{m}_{a} \cdot \bar{C}_{p, m a} \cdot \Delta T_{a}=-\sum_{\mathrm{fp}=1}^{3} \alpha_{a, \mathrm{fp}} \cdot A_{a, \mathrm{fp}} \cdot \bar{\theta}_{a, \mathrm{fp}}-\sum_{t=1}^{n_{t}} \alpha_{a, t}\left(\bar{T}_{a}-T_{s, t}\right) P_{a, t} \cdot \Delta z_{a, t}$

while the total mass transfer is

$\dot{m}_{a} \cdot \Delta W_{a}=-\sum_{\mathrm{fp}=1}^{3} \alpha_{D_{a, \mathrm{fp}}} \cdot A_{a, \mathrm{fp}} \cdot \bar{\omega}_{a, \mathrm{fp}}-\sum_{t=1}^{n_{t}} \alpha_{D_{a, t}}\left(\bar{W}_{a}-W_{\mathrm{sat}, s, t}\right) P_{a, t} \cdot \Delta z_{a, t}$

Rearranging Eqs. 14 and 15, taking into account LFTV approach for the air flow along the z-direction, gives.

$2\left(\bar{T}_{a}-T_{a}^{\mathrm{in}}\right)=-\sum_{\mathrm{fp}=1}^{3} \mathrm{NTU}_{a, \mathrm{fp}} \cdot \bar{\theta}_{a, \mathrm{fp}}-\sum_{t=1}^{n_{t}} \mathrm{NTU}_{a, t}\left(\bar{T}_{a}-T_{s, t}\right)$

where $\mathrm{NTU}_{a, \mathrm{fp}}=\frac{\alpha_{a, \mathrm{fp}} \cdot A_{a, \mathrm{fp}}}{\dot{m}_{a} \cdot \bar{C}_{p, m a}}$, and $\mathrm{NTU}_{a, t}=\frac{\alpha_{a, t} \cdot A_{a, t}}{\dot{m}_{a} \cdot \bar{C}_{p, m a}}$.

$2\left(\bar{W}_{a}-W_{a}^{\text {in }}\right)=-\sum_{\mathrm{fp}=1}^{3} \mathrm{NMTU}_{a, \mathrm{fp}} \cdot \bar{\omega}_{a, \mathrm{fp}}-\sum_{t=1}^{n_{t}} \mathrm{NMTU}_{a, t}\left(\bar{W}_{a}-W_{\mathrm{sat}, s, t}\right)$

where $\mathrm{NMTU}_{a, \mathrm{fp}}=\frac{\alpha_{a, \mathrm{fp}} \cdot A_{a, \mathrm{fp}}}{\dot{m}_{a} \cdot \bar{C}_{p, m a} \cdot L e^{2 / 3}}$, and NMTU ${ }_{a, t}=\frac{\alpha_{a, t} \cdot A_{a, t}}{\dot{m}_{a} \cdot \bar{C}_{p, m a} \cdot L e^{2 / 3}}$.

Eqs. 16 and 17 involve the term $\bar{\theta}_{a, \mathrm{fp}}$ which corresponds to $\bar{T}_{a}-\bar{T}_{\mathrm{fp}}$. The average fin temperature $\overline{T_{f}}$ can be obtained by integrating Eq. 6. This results in the following equation: 


$$
\bar{T}_{f}=\left\{\begin{array}{l}
\bar{T}_{\mathrm{fp} 1} \\
\bar{T}_{\mathrm{fp} 2} \\
\bar{T}_{\mathrm{fp} 3}
\end{array}\right\}_{f}\left[\begin{array}{c}
\frac{\int_{0}^{\zeta_{1}}\left[A\left(y_{\mathrm{fp} 1}, y_{\mathrm{fp} 2}, y_{\mathrm{fp} 3}\right)\right]_{1, \mathrm{j}} \cdot d y_{\mathrm{fp} 1}}{\zeta_{1}} \\
\frac{\int_{0}^{H_{f}-\left(\zeta_{1}+\zeta_{2}\right)}\left[A\left(y_{\mathrm{fp} 1}, y_{\mathrm{fp} 2}, y_{\mathrm{fp} 3}\right)\right]_{2, \mathrm{j}} \cdot d y_{\mathrm{fp} 2}}{H_{f}-\left(\zeta_{1}+\zeta_{2}\right)} \\
\frac{\int_{0}\left[A\left(y_{\mathrm{fp} 1}, y_{\mathrm{fp} 2}, y_{\mathrm{fp} 3}\right)\right]_{3, \mathrm{j}} \cdot d y_{\mathrm{fp} 3}}{\zeta_{2}}
\end{array}\right] \cdot\left[\begin{array}{l}
\bar{T}_{a} \\
T_{f B} \\
T_{f T} \\
\bar{\psi}
\end{array}\right]
$$

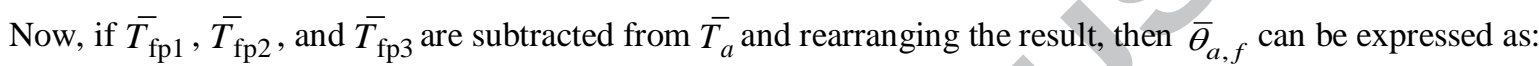

$$
\bar{\theta}_{a, f}=\left\{\begin{array}{l}
\bar{\theta}_{a, \mathrm{fp} 1} \\
\bar{\theta}_{a, \mathrm{fp} 2} \\
\bar{\theta}_{a, \mathrm{fp} 3}
\end{array}\right\}_{a, f}=\left\{\begin{array}{l}
\bar{T}_{a}-\bar{T}_{\mathrm{fp} 1} \\
\bar{T}_{a}-\bar{T}_{\mathrm{fp} 2} \\
\bar{T}_{a}-\bar{T}_{\mathrm{fp} 3}
\end{array}\right\}_{a, f}=[\mathrm{B}] \cdot\left[\begin{array}{l}
\bar{T}_{a} \\
T_{f B} \\
T_{f T} \\
\bar{\psi}
\end{array}\right]
$$

$[\mathrm{B}]$ is a $3 \times 4$ matrix that depends on the same parameters as $\left[A\left(\mathrm{y}_{\mathrm{fp} 1}, \mathrm{y}_{\mathrm{ff} 2}, \mathrm{y}_{\mathrm{fp} 3}\right)\right]$ excepting the spatial coordinates.

The components of $[\mathrm{B}]$ are presented in detail in Appendix A. $\bar{\theta}_{a, f}$ has an interesting characteristic, like $T_{f}(y)$, that it is expressed as a pseudo-linear function with respect to $\bar{T}_{a}, T_{f B}, T_{f T}, \bar{\psi}$. The advantage of using pseudo-linear functions is that they make it possible to solve all the proposed equations using a fast iterative method with good convergence.

Substituting Eq. 19 into Eqs. 16 and 17 gives the following expressions for average air temperature and humidity ratio, subsequently the outlet air temperature and humidity ratio, within each air cell.

$$
\begin{aligned}
& \bar{T}_{a}\left\{2+\mathrm{NTU}_{a, \mathrm{fp} 1} \cdot \mathrm{B}_{1,1}+\mathrm{NTU}_{a, \mathrm{fp} 2} \cdot \mathrm{B}_{2,1}+\mathrm{NTU}_{a, \mathrm{fp} 3} \cdot \mathrm{B}_{3,1}+\sum_{t=1}^{n_{t}} \mathrm{NTU}_{a, t}\right\}= \\
& \left\{\begin{array}{l}
2 T_{a}^{\text {in }}-\left[\mathrm{NTU}_{a, \mathrm{fp} 1} \cdot \mathrm{B}_{1,2}+\mathrm{NTU}_{a, \mathrm{p} 2} \cdot \mathrm{B}_{2,2}+\mathrm{NTU}_{a, \mathrm{fp} 3} \cdot \mathrm{B}_{3,2}\right] T_{f B}- \\
{\left[\mathrm{NTU}_{a, \mathrm{fp} 1} \cdot \mathrm{B}_{1,3}+\mathrm{NTU}_{a, \mathrm{fp} 2} \cdot \mathrm{B}_{2,3}+\mathrm{NTU}_{a, \mathrm{fp} 3} \cdot \mathrm{B}_{3,3}\right] T_{f T}-} \\
{\left[\mathrm{NTU}_{a, \mathrm{fp} 1} \cdot \mathrm{B}_{1,4}+\mathrm{NTU}_{a, \mathrm{fp} 2} \cdot \mathrm{B}_{2,4}+\mathrm{NTU}_{a, \mathrm{fp} 3} \cdot \mathrm{B}_{3,4}\right] \bar{\psi}+\sum_{t=1}^{n_{t}} \mathrm{NTU}_{a, t} \cdot T_{s, t}}
\end{array}\right\}
\end{aligned}
$$




$$
\begin{aligned}
& \bar{W}_{a}\left\{2+\mathrm{NMTU}_{a, \mathrm{fp} 1}+0+\mathrm{NMTU}_{a, \mathrm{fp} 3}+\sum_{t=1}^{n_{t}} \mathrm{NMTU}_{a, t}\right\}= \\
& \left\{\begin{array}{l}
2 W_{a}^{\mathrm{in}}+a_{a, f}\left[\mathrm{NMTU}_{a, \mathrm{fp} 1}+0+\mathrm{NMTU}_{a, \mathrm{fp} 3}\right]-\left[b_{a, f}\left(\mathrm{NMTU}_{a, \mathrm{fp} 1}\left(\mathrm{~B}_{1,1}-1\right)+0+\mathrm{NMTU}_{a, \mathrm{fp} 3}\left(\mathrm{~B}_{3,1}-1\right)\right)\right] \bar{T}_{a}- \\
{\left[b_{a, f}\left(\mathrm{NMTU}_{a, \mathrm{fp} 1} \cdot \mathrm{B}_{1,2}+0+\mathrm{NMTU}_{a, \mathrm{fp} 3} \cdot \mathrm{B}_{3,2}\right)\right] T_{f B}-\left[b_{a, f}\left(\mathrm{NMTU}_{a, \mathrm{fp} 1} \cdot \mathrm{B}_{1,3}+0+\mathrm{NMTU}_{a, \mathrm{fp} 3} \cdot \mathrm{B}_{3,3}\right)\right] T_{f T}-} \\
{\left[b_{a, f}\left(\mathrm{NMTU}_{a, \mathrm{fp} 1} \cdot \mathrm{B}_{1,4}+0+\mathrm{NMTU}_{a, \mathrm{fp} 3} \cdot \mathrm{B}_{3,4}\right)\right] \bar{\psi}+\sum_{t=1}^{n_{t}} \mathrm{NMTU}_{a, t} \cdot W_{\mathrm{sat}, s, t}}
\end{array}\right.
\end{aligned}
$$

It can be noticed in Eq. 21 that the terms correspond to the mass transfer between the second portion of the fin cell (fp2) and surrounding air are equal to zero. This is because this portion is always assumed to be totally dry.

\subsection{Solution Methodology}

After the initialization process, the iterative process begins, which consists of three steps. The first step is to calculate the outlet temperature and humidity ratio for all air cells using Eqs. 20 and 21, respectively. In the first iteration the dehumidifying conditions of the fins have not yet been evaluated, so all the fins are assumed to be totally dry. The second step is to calculate the tube wall cells' temperatures using Eq. 11. It can be seen that this equation considers the 2D heat conduction between the current tube wall cell and neighboring wall cells, which results in a system of linear equations involving all the tube wall cells temperatures. To solve this system of equations, the line-by-line iteration method is adopted in the current model [22].

The third step of the iterative process is to evaluate the dehumidifying condition of each fin cell (either to be totally dry, totally wet, or partially wet) then calculate its average temperature. Firstly, the fin cell dehumidifying condition is evaluated according to the fin cell roots temperatures and average dew point temperature of the surrounding air. After determining the actual fin cell condition, the following equations are applied to calculate the exact length for each fin portion.

$$
\zeta_{1}=\frac{1}{m} \cdot \ln \left\{\begin{array}{l}
\frac{-1}{2\left(\theta_{a, f T} e^{m H_{f}}-\theta_{a, f B}\right)} \times \\
{\left[\begin{array}{l}
-\bar{\theta}_{d p} e^{3 m H_{f}}+\bar{\theta}_{d p} e^{m H_{f}}+ \\
\sqrt{\bar{\theta}_{d p}^{2} e^{6 m H_{f}}-2\left(2 \theta_{a, f B} \theta_{a, f T} e^{m H_{f}}+\bar{\theta}_{d p}^{2}-2 \theta_{a, f B}^{2}\right) e^{4 m H_{f}}+}
\end{array} e^{-m H_{f}}\right.}
\end{array}\right\}
$$




$$
\zeta_{2}=H_{f}-\left\{\frac{1}{m} \cdot \ln \left[\begin{array}{l}
\frac{1}{2\left(\theta_{a, f T} e^{m H_{f}}-\theta_{a, f B}\right)} \times \\
\left(\begin{array}{l}
\bar{\theta}_{d p} e^{3 m H_{f}}-\bar{\theta}_{d p} e^{m H_{f}}+ \\
\sqrt[\bar{\theta}_{d p}^{2} e^{6 m H_{f}}-2\left(2 \theta_{a, f B} \theta_{a, f T} e^{m H_{f}}+\bar{\theta}_{d p}^{2}-2 \theta_{a, f B}^{2}\right) e^{4 m H_{f}}+]{\left(4 \theta_{a, f T}^{2} e^{2 m H_{f}}-4 \theta_{a, f B} \theta_{a, f T} e^{m H_{f}}+\bar{\theta}_{d p}^{2}\right) e^{2 m H_{f}}}
\end{array}\right) e^{-m H_{f}}
\end{array}\right]\right\}
$$

where $\bar{\theta}_{d p}=\bar{T}_{a}-\bar{T}_{d p}, \theta_{a, f B}=\bar{T}_{a}-T_{f B}$, and $\theta_{a, f T}=\bar{T}_{a}-T_{f T}$.

Finally, $\zeta_{1}$ and $\zeta_{2}$ are used in Eq. 19 to calculate the average fin cell temperature. It can be noted that the calculation process of obtaining the fin wall temperature field is explicit. The iterative process continues until the value of the residual converges to the required tolerance.

\section{NUMERICAL VERIFICATION OF THE FIN1D-MB MODEL}

In the current absence of other available external studies, the case studied by Hassan et al. [12, 13] was employed in the current verification process for the Fin1D-MB model, and later in the comparative study between the two numerical models. The case study consists of two evaporator tubes with tube length of $8.6 \mathrm{~cm}$, fin height of $8 \mathrm{~mm}$, fin thickness of $0.152 \mathrm{~mm}$, fin pitch of $1.59 \mathrm{~mm}$, and only one refrigerant pass. These geometrical specifications are sufficient enough to verify the proposed model and to identify the sources of deviations between the different modeling approaches; since the relevant dimensions to be discretized, in order to face the main prediction challenges which were discussed, are the fin height and depth.

The verification process consisted of two studies. The first one was the air-side verification study (V1), in which the conductivity of the tube and fin, and the refrigerant heat capacity rate were assumed to be infinite. This resulted to a uniform wall temperature along the y-direction that allowed performing a series of systematic checks against operational cases for which an analytical solution can be obtained. Under this situation, the fin and tube were discretized only in the direction of air flow (z-direction). The second one was the mesh independent verification study (V2), in which the effect of fin/air discretization, along the air flow direction, on the numerical solution was evaluated.

In the V1, the numerical solution was compared with the analytical one based on a zero heat capacity ratio heat exchanger ([16], ch. 11, pp. 723-730), where $\varepsilon=1-\exp (-\mathrm{NTU})$. 

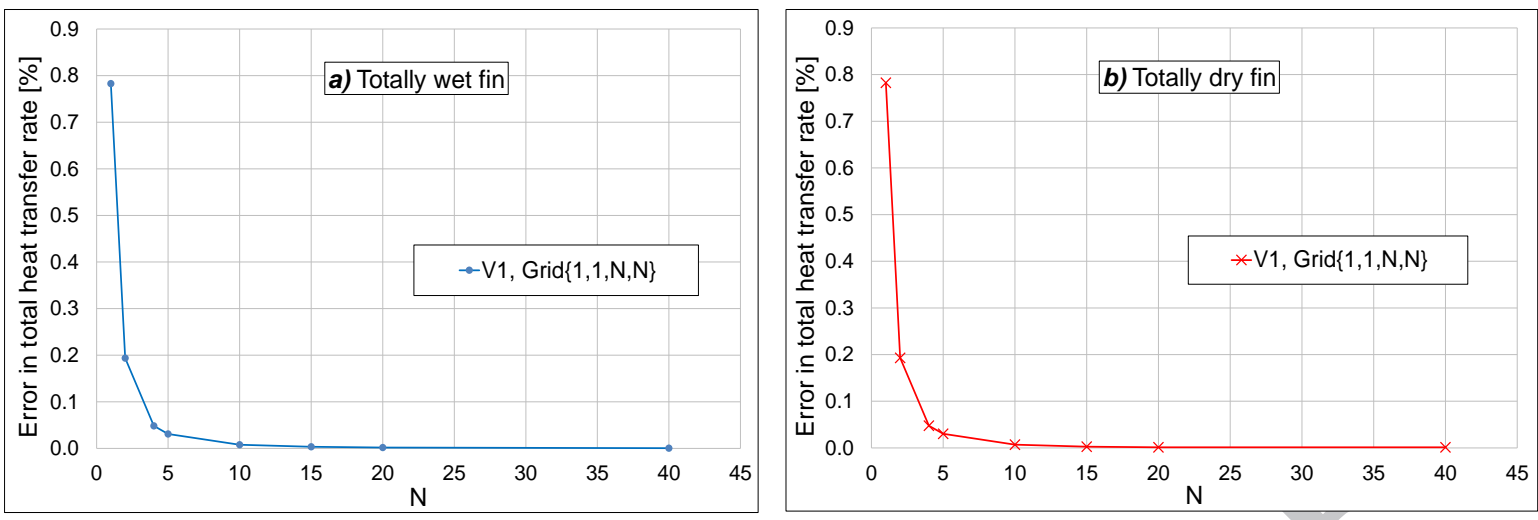

Fig. 4-V1 results. (a) For a totally wet fin. (b) For a totally dry fin.
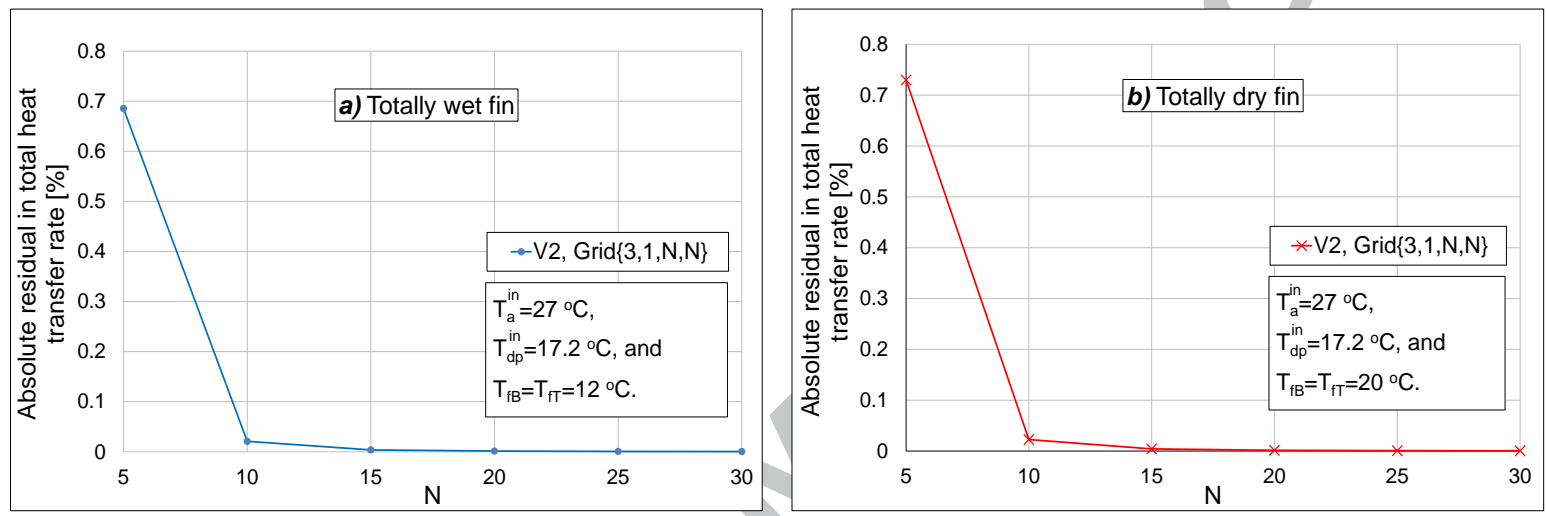

Fig. 5 - V2 results. (a) For a totally wet fin. (b) For a totally dry fin.

Fig. 4 illustrates the results of V1. It can be noticed that the error in total heat transfer rate, for both cases totally wet and dry, rapidly diminishes after $\mathrm{N}=5$; where $\mathrm{N}$ represents the number of fin/air and tube wall cells in the $\mathrm{z}$ direction. The results of V2 are shown in Fig. 5, where the change of absolute residual in total heat transfer rate is illustrated with respect to $\mathrm{N}$. It can be seen that the residual steadily tends to zero after $\mathrm{N}=10$.

\section{COMPARISON OF THE AIR-SIDE HEAT TRANSFER RESULTS BETWEEN THE FIN1D-MB AND FIN2D-W MODELS}

In this study the air-side heat transfer results from the present Fin1D-MB model are compared with the results of Fin2D-W model. The evaporator piece in the case study is discretized into a grid of $\{3,1,10,10\}$, based on the Fin1D-MB model verification study. For the Fin2D-W model, the evaporator piece is subdivided into three segments along the refrigerant flow direction. Each segment consists of two streams of refrigerant (upper and lower) that are split into only one channel in the air flow direction; two flat tubes (upper and lower) that are divided into ten cells in the air flow direction; and both air stream and fin, which are discretized in twodimensions: thirty cells along the fin height and ten cells in the air flow direction. This is summarized as a grid of $\{3,1,10,30,10\}$ [12]. It can be observed that in both models the fin and air flow are discretized into ten cells in the air flow direction. To allow a fair and clear comparison in same conditions between the two models, the 
following assumptions are made: the tube temperatures are assumed to be known and specified, the air-side sensible heat transfer coefficient is constant, and the properties of moist air are also constant.

Three cases covering a wide range of refrigeration and air conditioning applications were selected to represent different inlet air conditions to the evaporator, as shown in Table 1.

Table 1 - Inlet air conditions used in the simulations.

\begin{tabular}{|c|c|c|c|c|c|}
\hline & $\begin{array}{c}T_{a}^{\mathrm{in}} \\
{\left[{ }^{\circ} \mathrm{C}\right]}\end{array}$ & $\begin{array}{l}\mathrm{RH}_{a}^{\mathrm{in}} \\
{[\%]}\end{array}$ & $\begin{array}{l}T_{d p, a}^{\mathrm{in}} \\
{\left[{ }^{\circ} \mathrm{C}\right]}\end{array}$ & $\begin{array}{c}\mathrm{G}_{\mathrm{a}} \\
{\left[\mathrm{kg} \mathrm{m}^{-2} \mathrm{~s}^{-1}\right]}\end{array}$ & $\begin{array}{c}\text { Inlet pressure } \\
{[\mathrm{kPa}]}\end{array}$ \\
\hline Case I & 14 & 90 & 12.39 & & 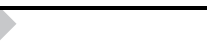 \\
\hline Case II & 27 & 55 & 17.20 & 3.34 & 100 \\
\hline Case III & 40 & 67 & 32.69 & 0 & \\
\hline
\end{tabular}

Based on the inlet air conditions (see Table 1) and specifications of case study (see Section 3), the air-side sensible heat transfer coefficient was estimated to be $48 \mathrm{~W} \mathrm{~m}^{-2} \mathrm{~K}^{-1}$. This value was evaluated with convection correlations for laminar flow in non-circular tubes (Bergman et al. [16], ch.8, pp. 552-555). The hydraulic diameter of the air passage between any two successive fins was adopted for Reynolds number calculation. Since the air velocity does not change, the value remained the same for all the cases studied. For moist air the Lewis number is close to unity [23], so a Lewis number of unity was assumed in the current study.

In the current comparative study, the lower tube temperature $\mathrm{T}_{1 \mathrm{t}}$ was always assumed to be constant, while the upper tube temperature $T_{u t}$ was gradually increased until reaching the inlet air temperature for each case. The difference between upper tube and lower tube temperatures is defined as the superheat (SH) in the current work. To show representative values of $\mathrm{SH}$, different sets of lower tube temperatures were chosen for each case. This allows to have similar differences between the lower tube temperature and dew point of inlet air. The results of the two models are compared below.

In Figs. $6-8$ (part a) the relative deviations in sensible heat transfer rate, based on the Fin2D-W model results, for the three cases under study are plotted against superheat values. It can be seen from these figures that the Fin1D-MB model always overpredicts the sensible heat transfer rate in an almost constant trend, regardless of the superheat value. The average values of these deviations for Cases I, II, and III are $4.23 \%, 4.10 \%$, and $4.12 \%$ respectively. It can be also noticed that the deviations are almost independent of inlet air conditions. The main source of these deviations is the assumption of uniform air temperature between the tubes adopted by the Fin1DMB model. It is worth mentioning that Martínez-Ballester et al. [18] reported similar deviations in the sensible heat transfer rate in their comparative study of different numerical models for $\mathrm{CO}_{2}$ gas coolers. 

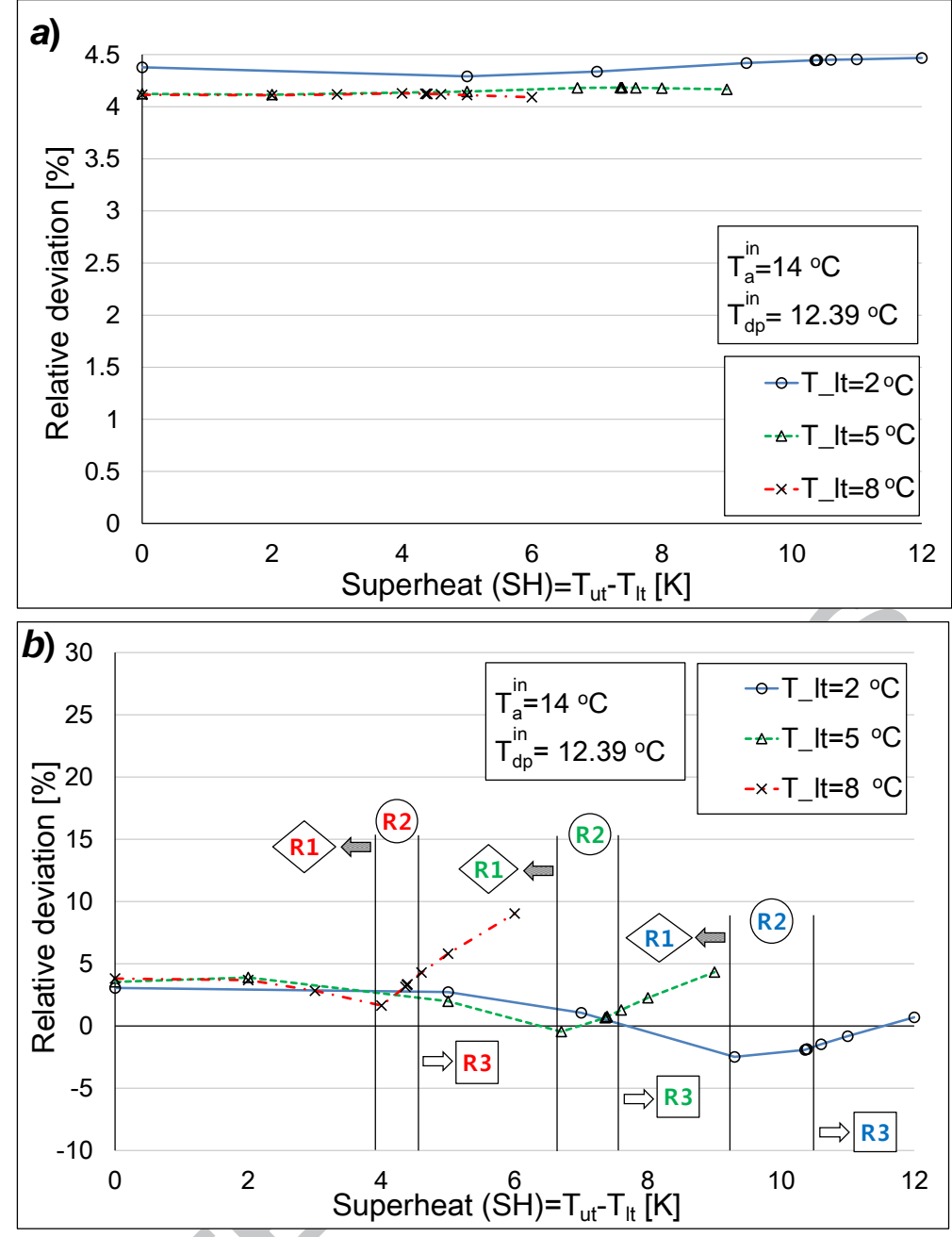

Fig. 6 - Relative deviations in (a) sensible and (b) latent heat transfer rates between the Fin1D-MB and Fin2D-W models, for Case I.

The relative deviations in latent heat transfer rate between the two models are depicted in Figs. $6 \mathrm{~b}, 7 \mathrm{~b}$, and $8 \mathrm{~b}$.

The results are divided into three regions according to the fin condition predicted by each model: the first region (R1) in which the fin is assumed to be totally wet by the two models; the second region (R2) in which the Fin1D-MB model assumes partially wet fin condition, while the Fin2D-W model still assumes totally wet fin condition; the third region (R3) in which both models assume partially wet fin condition. 

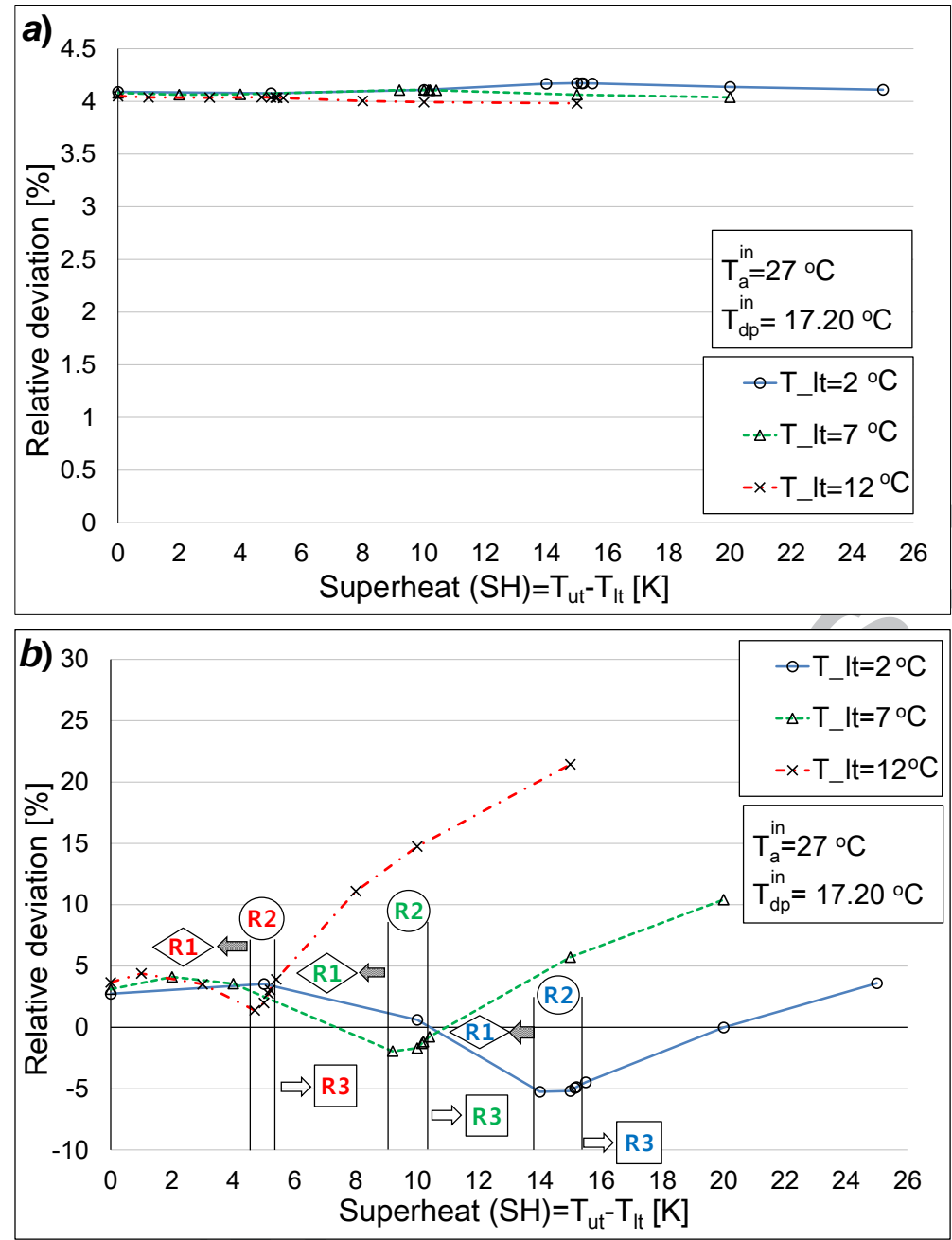

Fig. 7 - Relative deviations in (a) sensible and (b) latent heat transfer rates between the Fin1D-MB and Fin2D-W models, for Case II.

At the beginning of $\mathrm{R} 1, \mathrm{SH}=0 \sim 4 \mathrm{~K}$, the Fin1D-MB always overpredicts the amount of latent heat transfer, and the deviations between the two models follow a steady trend in the three cases studied. The Fin1D-MB model, unlike the Fin2D-W model, assumes a uniform air humidity ratio along the fin height. This assumption contributes to the deviations in latent heat transfer rate in this region. With a further rise in superheat, the Fin1DMB model tends to convert the fin condition from totally wet to partially wet earlier than the Fin2D-W model. Consequently, the amount of latent heat predicted by the Fin1D-MB model starts to drop, but is still higher than the Fin2D-W model. However, as the lower tube temperature continues to drop, the Fin1D-MB model starts to predict lower latent heat transfer rate compared to the Fin2D-W model. This situation results in negative deviations, for the most cases, at the end of R1, as shown in Figs. 6-8 (part b). In R1, the relative deviations, based on the Fin2D-W model results, in latent heat transfer rate are up to $3.90 \%, 4.40 \%$, and $4.80 \%$ for Cases I, II, and III, respectively. Whereas, the values of the average relative deviation (ARD) in latent heat transfer rate for the three lower tube temperatures for Cases I, II, and III are 2.52\%, 2.30\%, and 2.80\%, respectively. 

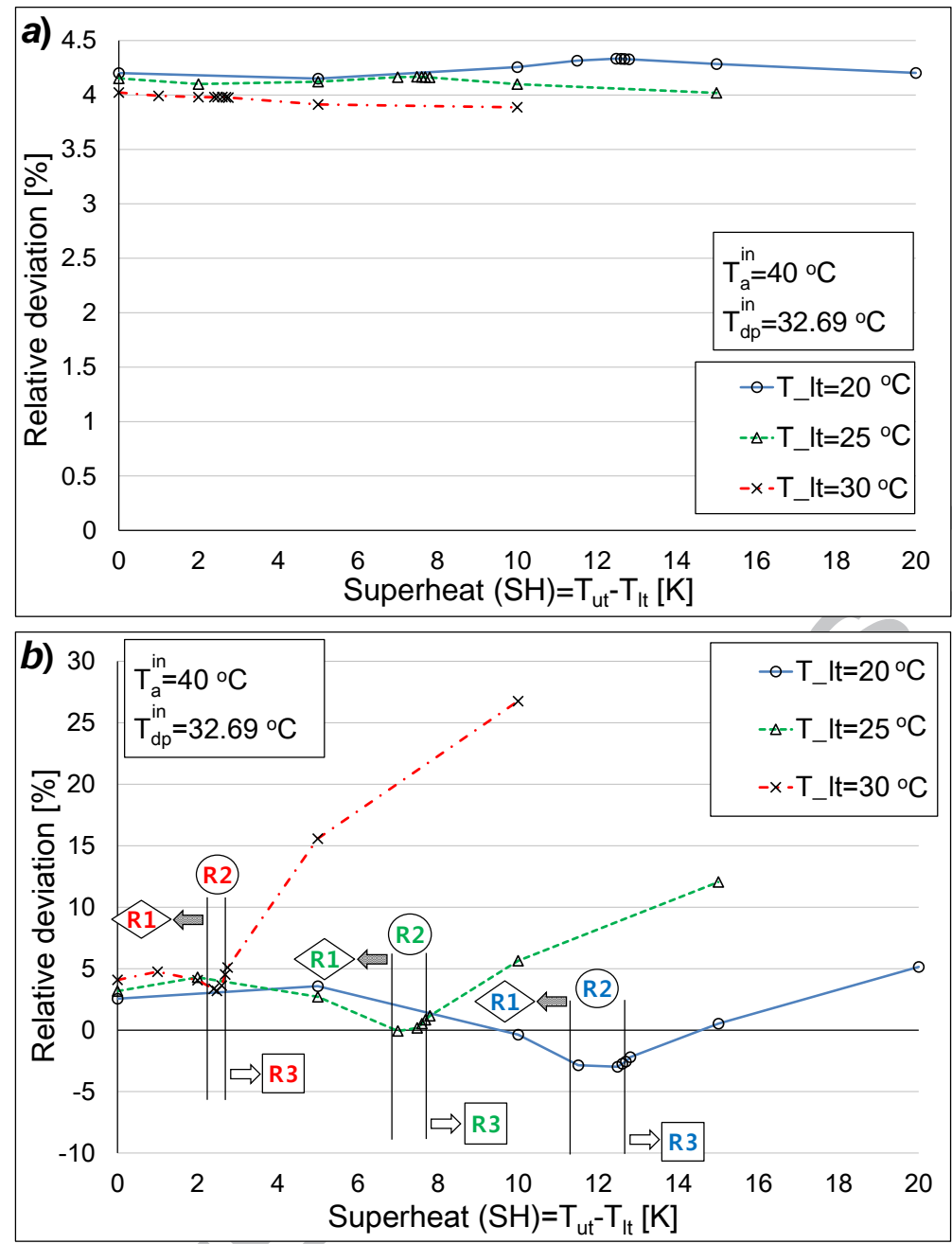

Fig. 8 - Relative deviations in (a) sensible and (b) latent heat transfer rates between the Fin1D-MB and Fin2D-W models, for Case III.

The R2 begins with the first anticipation of a partially wet fin by the Fin1D-MB model, while the Fin2D-W model is still treating the fin as totally wet within this region. Compared to the Fin2D-W model, this premature anticipation of a partially wet condition could be interpreted as being due to the different schemes used by each model to discretize the fin and air flow. However, this disagreement is negligible, since the ARD values in latent heat transfer rate for the three lower tube temperatures for Cases I, II, and III are $0.41 \%,-1.44 \%$, and $0.42 \%$, respectively. Nevertheless, the drop in the lower tube temperature could result in a lower prediction of latent heat transfer rate in R2, for some specific conditions, compared to the Fin2D-W model. This can be observed, for example, in Case I when $\mathrm{T}_{1 \mathrm{l}}=2{ }^{\circ} \mathrm{C}$.

When the Fin2D-W model starts to treat the fin as partially wet, the third region R3 comes into action. Although both models have a similar capability to distinguish between the wet and dry portions along the fin height, the deviations in latent heat transfer rate in this region start to rise with higher superheat, as shown in Figs. 6-8 (part b). To better identify the source of these deviations, Fig. 9 shows the fin temperature profile and mass flux 
of condensed water, at half the fin depth, for a specific point in R3. This point represents Case II at the most extreme condition, where $\mathrm{T}_{\mathrm{lt}}=12{ }^{\circ} \mathrm{C}$ and $\mathrm{SH}=15 \mathrm{~K}$.

Fig. 9 shows that the two models predict similar fin temperature profiles and dehumidifying condition, where approximately $35 \%$ of the fin is wet while the rest is dry. However, the main difference between the two models is that the Fin2D-W model allows for the non-mixed air along fin height and humidity ratio gradients near the tubes, unlike the Fin1D-MB model.

The air cells near the bottom tube are very close to the saturation condition at the tube surface temperature. So, the potential of mass transfer, the humidity ratio difference, tends to zero with approaching the lower tube surface. This subsequently results to that the Fin1D-MB model clearly overpredicts the amount of condensed water within approximately $20 \%$ of the fin height near the bottom tube, as shown in Fig. $9 \mathrm{~b}$. Generally, in the $\mathrm{R} 3$, the ARD values in latent heat transfer rate for the three lower tube temperatures for Cases I, II, and III are $2.82 \%, 5.90 \%$, and $7.75 \%$, respectively.

Since these deviations are related to the fin portion near the lower tube, then it will affect the latent heat transfer rate more as the wet region becomes smaller. This is the reason why the deviations between the two models increase with superheat. Anyhow, the effect of these deviations on the total heat transfer rate will become smaller since the latent heat contribution decreases with the increase in superheat.

From the former discussion, we can conclude that analyzing separately the contributions of sensible and latent heat transfer may be misleading. Therefore, it is also necessary to illustrate the relative deviations in total heat transfer rate between the two models for the three inlet air cases studied, as shown in Fig. 10. 

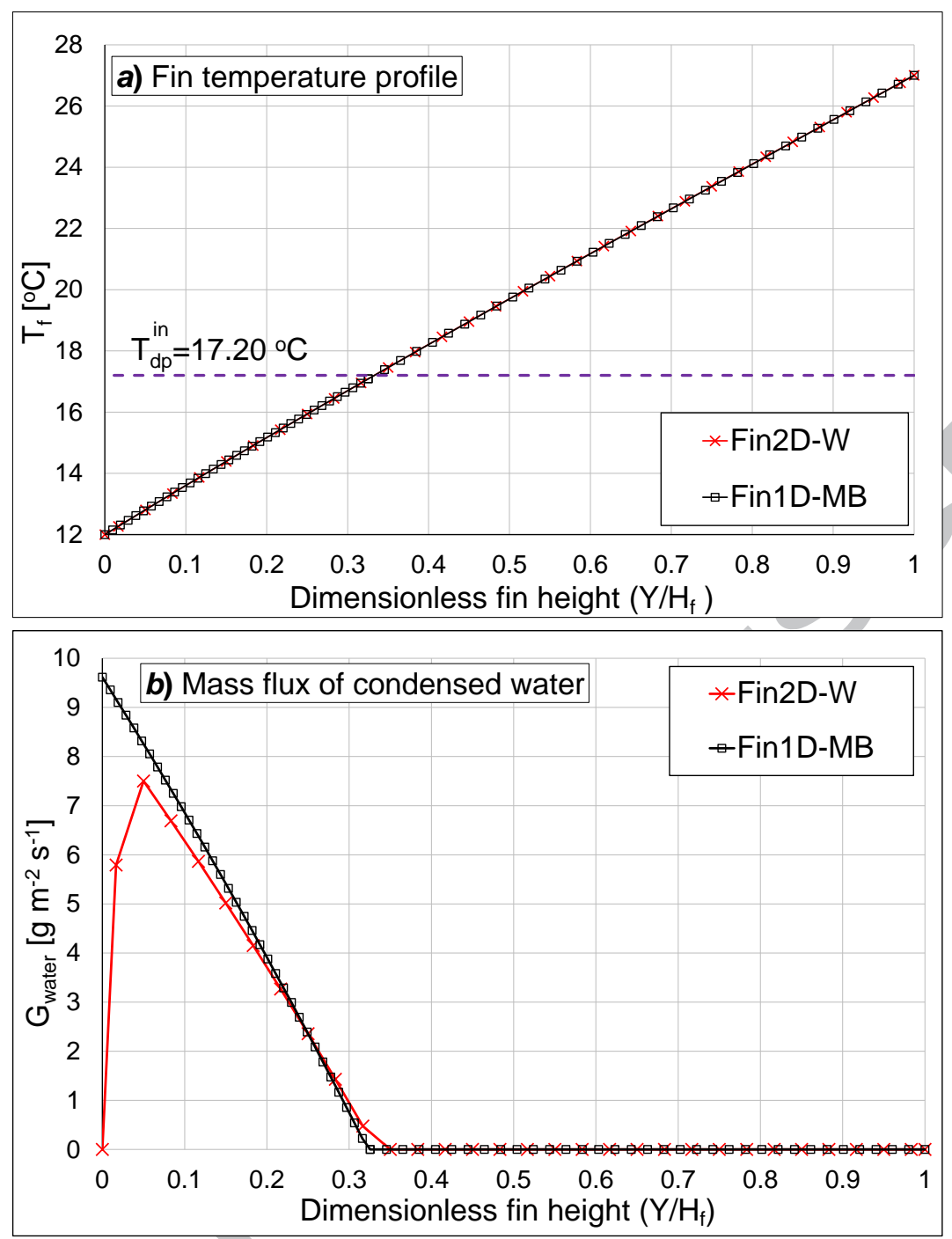

Fig. 9- (a) Fin temperature profile and (b) mass flux of condensed water, at half the fin depth, for a point in R3. This represents Case II, when $\mathrm{T}_{\mathrm{It}}=12^{\circ} \mathrm{C}$ and $\mathrm{SH}=15 \mathrm{~K}$.

As shown before in Figs. 6-8 (part b), the maximum relative deviations in latent heat transfer rate for Cases I, II, and III are 9\%, 21.40\%, and 26.80\%, respectively. However, it can be noted from Fig. 10 that the relative deviations in total heat transfer rate, for the same situations, dropped down to $6.20 \%, 7.40 \%$, and $10 \%$ for Cases I, II, and III, respectively.

The deviations in the total heat transfer rate between the Fin1D-MB and Fin2D-W models are still relatively high. However, they are much better compared to the deviations between the classical $\varepsilon$-NTU approach and the Fin2D-W model, which were reported by Hassan et al. [13]. For the same cases studied and same air-side sensible heat transfer coefficient, the deviations in the total heat transfer rate between the $\varepsilon-\mathrm{NTU}$ and Fin2D-W models were up to $52 \%$. 

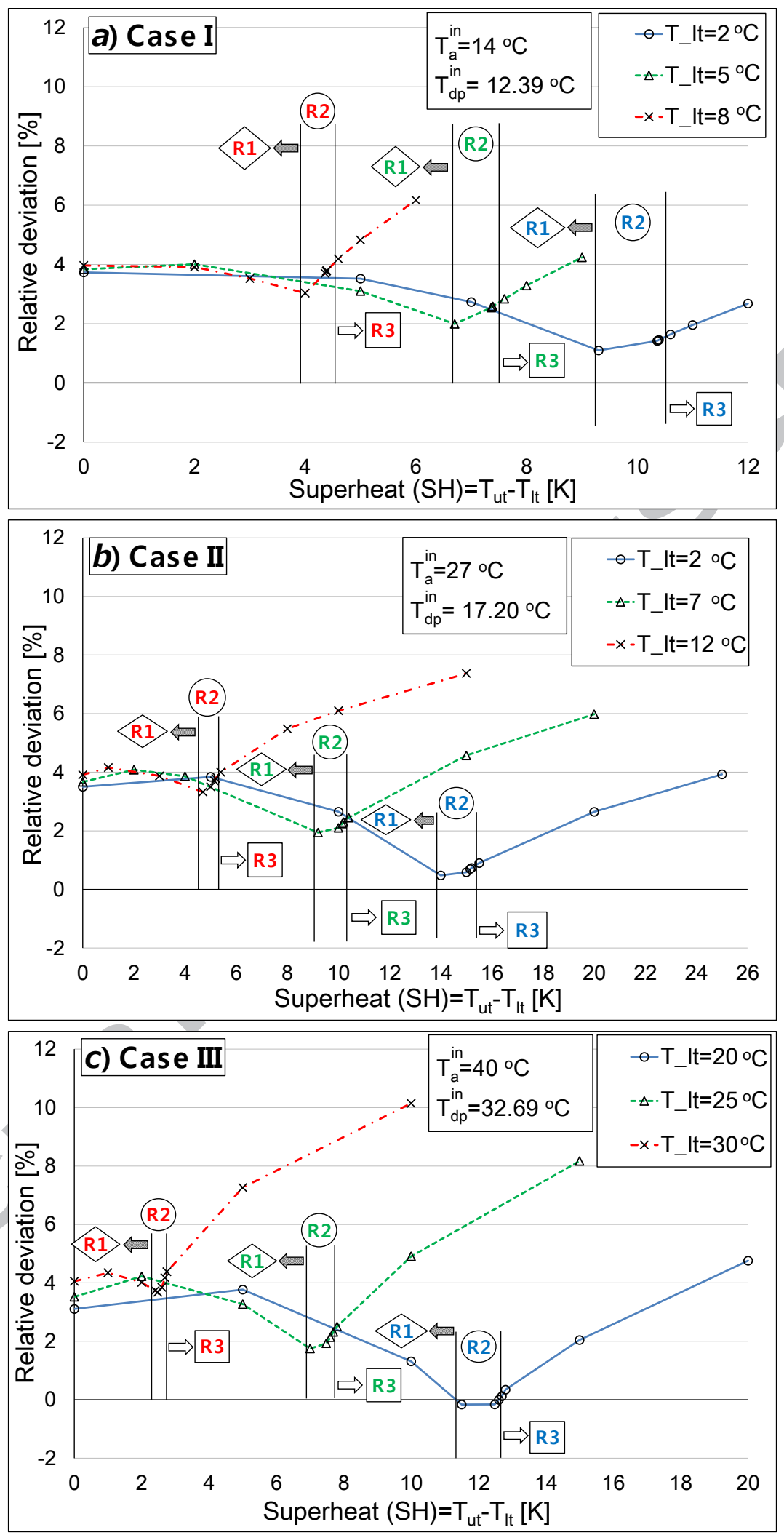

Fig. 10 - Relative deviations in total heat transfer rate between the Fin1D-MB and Fin2D-W models, for (a) Case I, (b) Case II, and (c) Case III.

Also, it should be considered that the case studied comprises only two tubes. Additionally, in the current comparative study, the superheat is assumed to affect the entire piece of the evaporator. However, in actual 
evaporators the superheat region occupies a small area compared to the evaporator's total area. Moreover, extreme $\mathrm{SH}$ values are considered in the current study, up to $\approx 25 \mathrm{~K}$. However, it is expected that these deviations will significantly decrease in the case of evaluating a complete minichannel evaporator, and this will be the next objective for the authors.

\section{CONCLUSIONS}

A numerical model (Fin1D-MB) for analyzing the air-side performance of minichannel evaporators was developed and verified. The Fin1D-MB model is based on a more comprehensive two-dimensional model (Fin2D-W) which was introduced by Hassan et al. $[12,13]$; however, innovative discretization techniques were utilized to reduce the computation time while maintaining a reasonable solution accuracy. A comparison of the air-side heat transfer results between the Fin1D-MB and Fin2D-W models was made under different dehumidifying conditions and values of superheat. The general conclusions of this study are:

- The Fin1D-MB model significantly saves the computation time compared to the Fin2D-W model, with speed ratio of 1:20 for all the cases studied. This advantage is derived from using the fin theory, which substantially reduces the complexity of the fin/air discretization scheme.

- The proposed model also predicts the actual dehumidifying condition of the fin quite well, as a consequence of adopting the moving boundary technique along the fin height.

- In the fully wet fin region, the Fin1D-MB model slightly overpredicts the total heat transfer rate, compared to the Fin2D-W model. The relative deviations between the two models, in this region, were up to $4.34 \%$ for the three cases studied.

- In the partially wet fin region, the relative deviations in total heat transfer rate increased by up to $10 \%$. Nevertheless, these deviations are expected to decrease while evaluating a complete minichannel evaporator.

- Although both models predict similar fin temperature profiles and dehumidifying conditions, the main source of the deviations in heat transfer results, especially in latent heat transfer rate, is the assumption of uniform air temperature and humidity ratio along the fin height adopted by the Fin 1D-MB model.

\section{ACKNOWLEDGMENTS}


The authors would like to gratefully acknowledge the financial support from the Spanish Ministry of Economy and Finance to the project number DPI2011-26771-C02-01. The proofreading of this paper was funded by the Centro de Lenguas, Universitat Politècnica de València.

\section{REFERENCES}

[1] Kim, M.H., Bullard, C.W. 2001. Development of a microchannel evaporator model for a $\mathrm{CO}_{2}$ airconditioning system. Energy, 26, 931-948.

[2] Wu, X.M., Webb, R.L. 2002. Thermal and hydraulic analysis of a brazed aluminum evaporator. Applied Thermal Engineering, 22, 1369-1390.

[3] Jin, J., Chen, J., Chen, Z. 2011. Development and validation of a microchannel evaporator model for a $\mathrm{CO}_{2}$ air-conditioning system. Applied Thermal Engineering, 31, 137-146.

[4] Yun, R., Kim, Y., Park, C. 2007. Numerical analysis on a microchannel evaporator designed for $\mathrm{CO}_{2}$ airconditioning systems. Applied Thermal Engineering, 27, 1320-1326.

[5] Gossard, J.J., Han, X., Ramalingam, M., Sommers, A.D. 2013. Investigating the thermal-hydraulic performance of new refrigerant mixtures through numerical simulation of minichannel and microchannel evaporators. Applied Thermal Engineering, 50(1), 1291-1298.

[6] Ren, T., Ding, G., Wang, T., Hu, H. 2013. A general three-dimensional simulation approach for microchannel heat exchanger based on graph theory. Applied Thermal Engineering, 59, 660-674.

[7] Huang, L., Bacellar, D., Aute, V., Radermacher, R. 2015. Variable geometry microchannel heat exchanger modeling under dry, wet and partially wet surface conditions accounting for tube-to-tube heat conduction. Science and Technology for the Built Environment, 21, 703-717.

[8] McQuiston, F.C. 1975. Fin efficiency with combined heat and mass transfer. ASHRAE Transactions, 81(1), $350-355$.

[9] Elmahdy, A.H., Biggs, R.C. 1983. Efficiency of extended surfaces with simultaneous heat transfer and mass transfer. ASHRAE Journal, 89, 135-143.

[10] Wu, G., Bong, T.Y. 1994. Overall Efficiency of a straight fin with combined heat and mass transfer. ASHRE Transaction, 100, 367-374.

[11] Sharqawy, M.H., Zubair, S.M. 2008. Efficiency and optimization of straight fins with combined heat and mass transfer - An analytical solution. Applied Thermal Engineering, 28, 2279-2288. 
[12] Hassan, A.H., Martínez-Ballester, S., Gonzálvez-Maciá, J. 2015. A Comparative Study between a twodimensional numerical minichannel evaporator model and a classical effectiveness-NTU approach under different dehumidifying conditions. Science and Technology for the Built Environment, 21(5), 681-692.

[13] Hassan, A.H., Martínez-Ballester, S., Gonzálvez-Maciá, J. 2016. Two-dimensional numerical modeling for the air-side of minichannel evaporators accounting for partial dehumidification scenarios and tube-to-tube heat conduction. International Journal of Refrigeration, 67, 90-101.

[14] Martínez-Ballester, S., Corberán, J.M., Gonzálvez-Maciá, J., Domanski, P.A. 2011. Impact of classical assumptions in modelling a microchannel gas cooler. International Journal of Refrigeration, 34(8), p. 18981910.

[15] Asinari, P., Cecchinato, L., Fornasieri, E. 2004. Effects of thermal conduction in microchannel gas coolers for carbon dioxide. International Journal of Refrigeration, 7, 577-586.

[16] Bergman, T.L., Lavine, A.S., Incropera, F.P., DeWitt, D.P. 2011. Fundamentals of Heat and Mass Transfer. 7th edition. John Wiley and Sons, New Jersey.

[17] Martínez- Ballester, S., Corberán, J.M., Gonzálvez-Macia, J. 2013. Numerical model for microchannel condensers and gas coolers: Part I - Model description and validation. International Journal of Refrigeration, 36, 173-190.

[18] Martínez-Ballester, S., Corberán, J.M., Gonzálvez-Macia, J. 2013. Numerical model for microchannel condensers and gas coolers: Part II - Simulation studies and model comparison. International Journal of Refrigeration, 36, 191-202.

[19] Kuehn, T.H., Ramsey, J.W., Threlkeld, J.L. 1998. Thermal Environmental Engineering. 3rd edition. Prentice-Hall Inc., Upper Saddle River, NJ.

[20] Corberán, J.M., De-Cordoba, P.F., Gonzálvez-Macia, J., Alias, F. 2001. Semiexplicit Method for Wall Temperature Linked Equations (SEWTLE): A General Finite- Volume Technique for the Calculation of Complex Heat Exchangers. Numerical Heat Transfer, Part B: Fundamentals, 40(1), 37-59.

[21] Lee, J., Domanski, P.A. 1997. Impact of Air and Refrigerant Maldistributions on the Performance of Finned-Tube Evaporators with R-22 and R-407C. Report No.: DOE/CE/23810-23881.

[22] Patankar, S.V. 1980. Numerical Heat Transfer and Fluid Flow. Hemisphere, New York.

[23] Coney, J.E.R., Sheppard, C.G.W., El-Shafei, E.A.M. 1989. Fin performance with condensation from humid air: a numerical investigation. International Journal of Heat and Fluid Flow, 10, 224-231. 


\section{APPENDIX A: Matrix [B] Coefficients}

This appendix shows the components of matrix $[\mathrm{B}]_{3 \times 4}$ which is employed in Eq. 19 to evaluate the average temperature for a fin cell.

\section{A.1. Components of $B_{1, j}$}

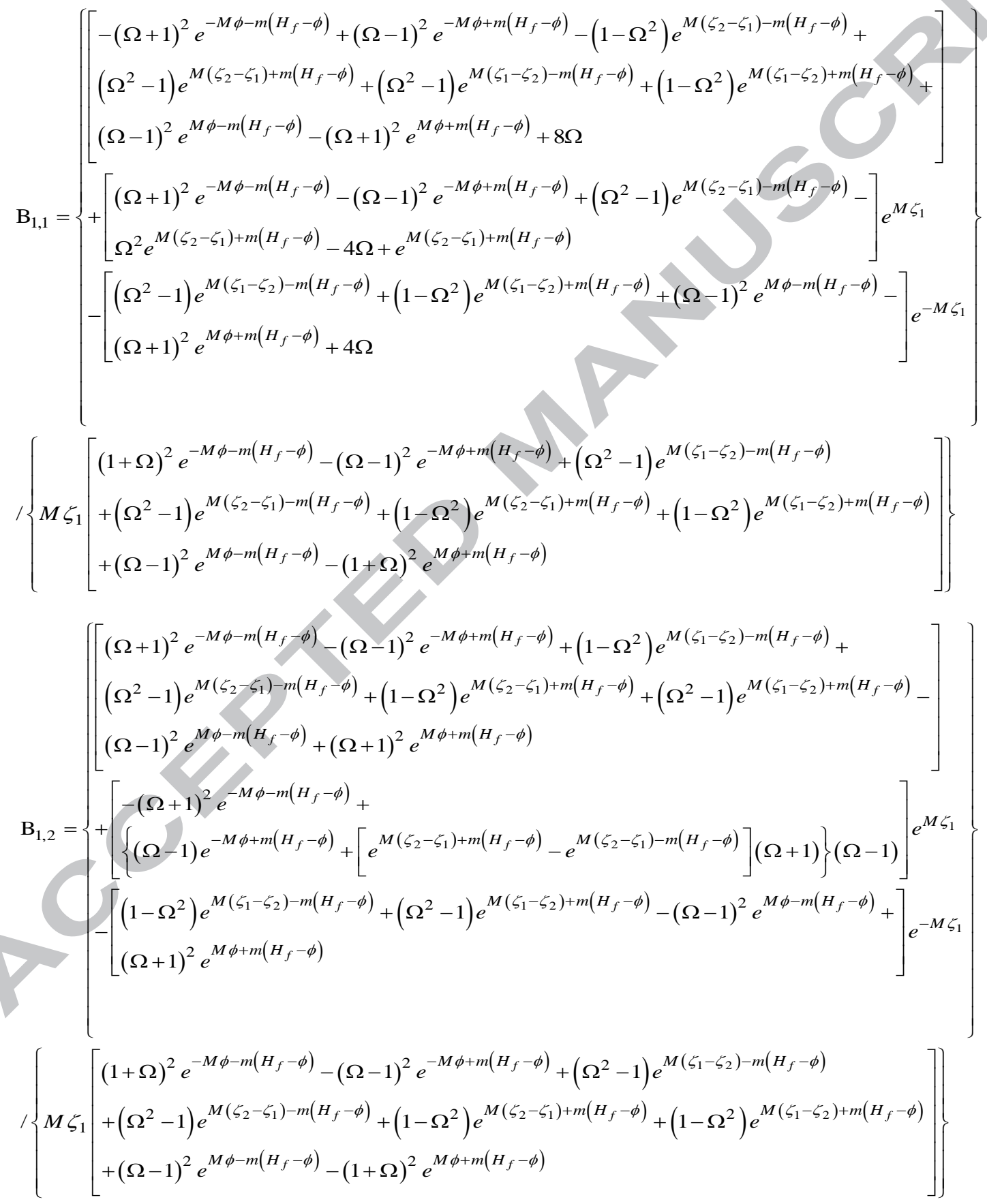




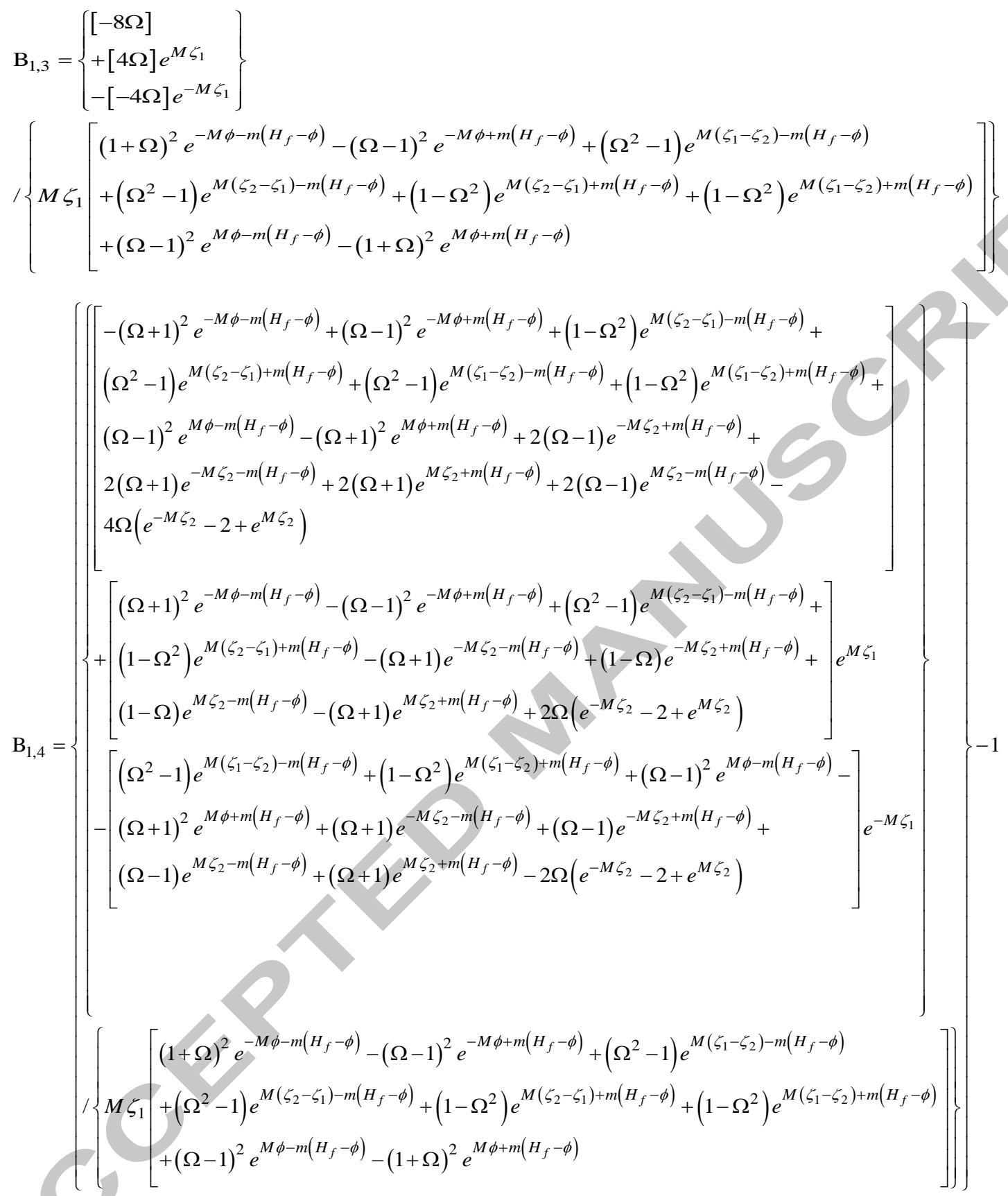




\section{A.2. Components of $\mathbf{B}_{2, j}$}

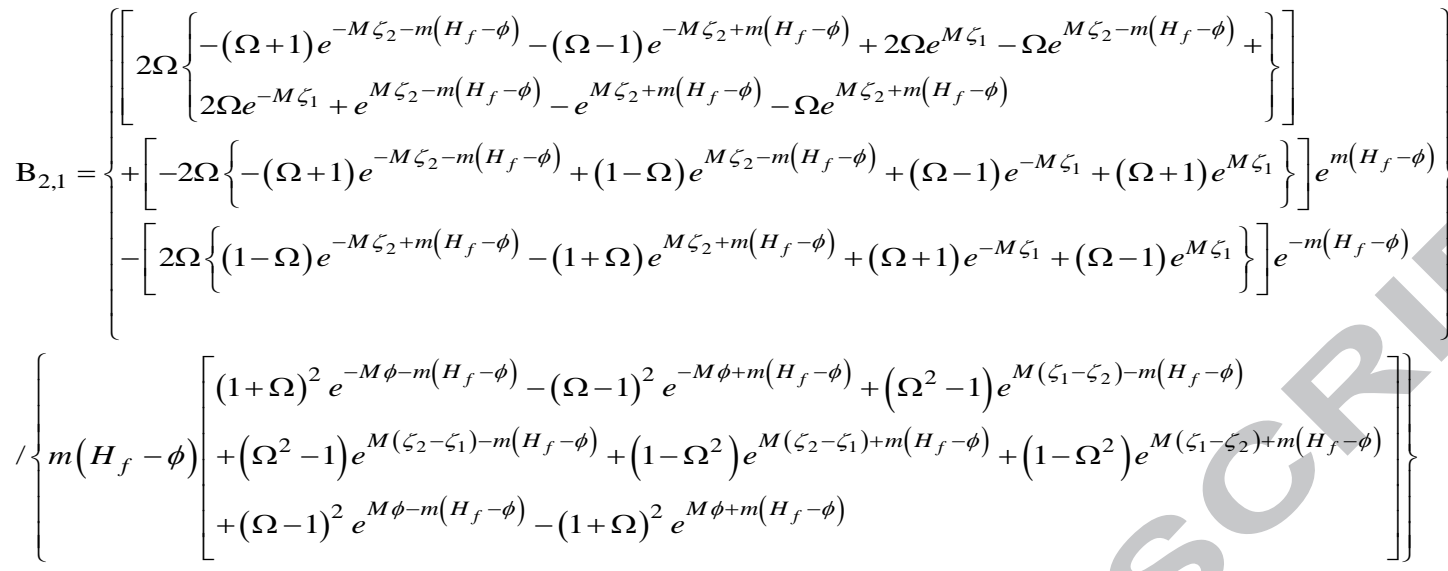

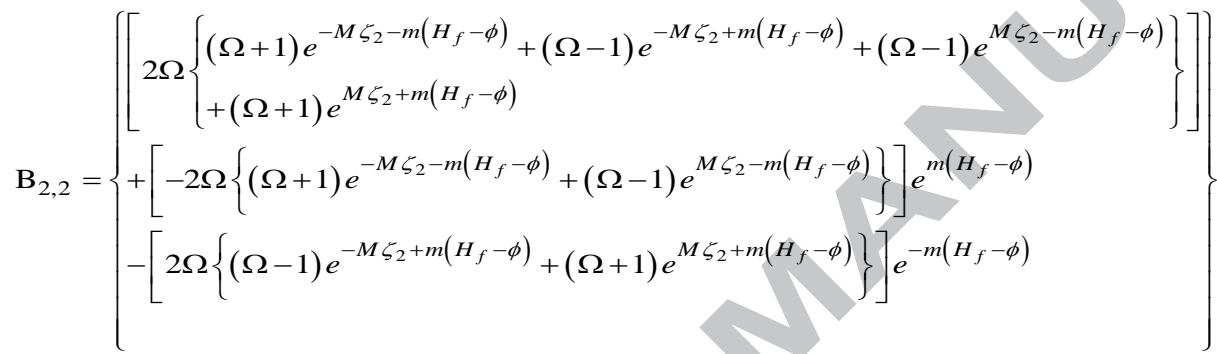

$$
\begin{aligned}
& /\left\{m\left(H_{f}-\phi\right)\left[\begin{array}{l}
(1+\Omega)^{2} e^{-M \phi-m\left(H_{f}-\phi\right)}-(\Omega-1)^{2} e^{-M \phi+m\left(H_{f}-\phi\right)}+\left(\Omega^{2}-1\right) e^{M\left(\zeta_{1}-\zeta_{2}\right)-m\left(H_{f}-\phi\right)} \\
+\left(\Omega^{2}-1\right) e^{M\left(\zeta_{2}-\zeta_{1}\right)-m\left(H_{f}-\phi\right)}+\left(1-\Omega^{2}\right) e^{M\left(\zeta_{2}-\zeta_{1}\right)+m\left(H_{f}-\phi\right)}+\left(1-\Omega^{2}\right) e^{M\left(\zeta_{1}-\zeta_{2}\right)+m\left(H_{f}-\phi\right)} \\
+(\Omega-1)^{2} e^{M \phi-m\left(H_{f}-\phi\right)}-(1+\Omega)^{2} e^{M \phi+m\left(H_{f}-\phi\right)}
\end{array}\right]\right\} \\
& \mathbf{B}_{2,3}=\left\{\begin{array}{l}
{\left[-4 \Omega^{2}\left(e^{M \zeta_{1}}+e^{-M \zeta_{1}}\right)\right]} \\
+\left[2 \Omega\left\{(\Omega-1) e^{-M \zeta_{1}}+(\Omega+1) e^{M \zeta_{1}}\right\}\right] e^{m\left(H_{f}-\phi\right)} \\
-\left[-2 \Omega\left\{(\Omega+1) e^{-M \zeta_{1}}+(\Omega-1) e^{M \zeta_{1}}\right\}\right] e^{-m\left(H_{f}-\phi\right)}
\end{array}\right\} \\
& \left\{m\left(H_{f}-\phi\right)\left[\begin{array}{l}
(1+\Omega)^{2} e^{-M \phi-m\left(H_{f}-\phi\right)}-(\Omega-1)^{2} e^{-M \phi+m\left(H_{f}-\phi\right)}+\left(\Omega^{2}-1\right) e^{M\left(\zeta_{1}-\zeta_{2}\right)-m\left(H_{f}-\phi\right)} \\
+\left(\Omega^{2}-1\right) e^{M\left(\zeta_{2}-\zeta_{1}\right)-m\left(H_{f}-\phi\right)}+\left(1-\Omega^{2}\right) e^{M\left(\zeta_{2}-\zeta_{1}\right)+m\left(H_{f}-\phi\right)}+\left(1-\Omega^{2}\right) e^{M\left(\zeta_{1}-\zeta_{2}\right)+m\left(H_{f}-\phi\right)} \\
+(\Omega-1)^{2} e^{M \phi-m\left(H_{f}-\phi\right)}-(1+\Omega)^{2} e^{M \phi+m\left(H_{f}-\phi\right)}
\end{array}\right]\right\}
\end{aligned}
$$




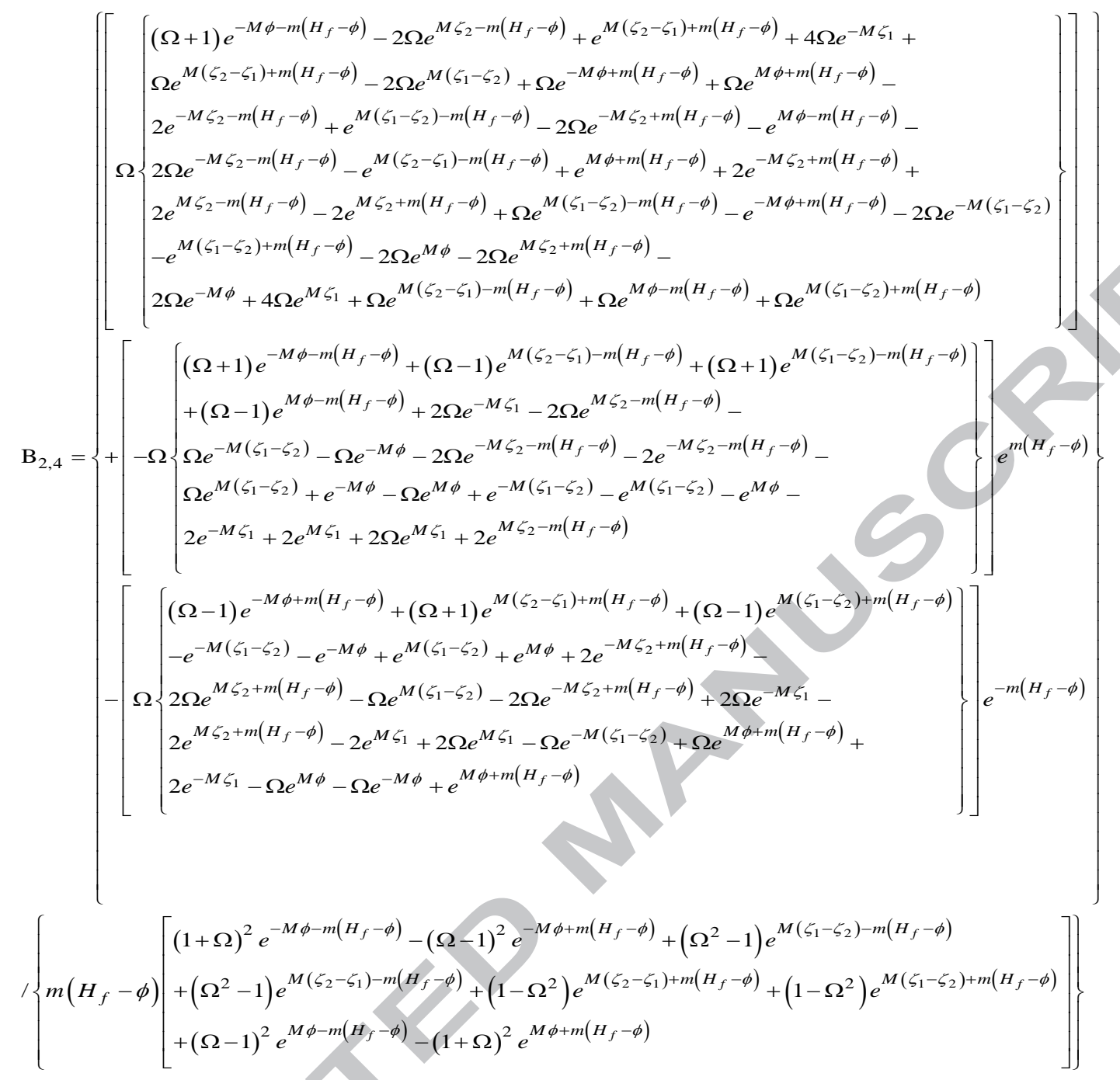




\section{A.3. Components of $\mathbf{B}_{3, j}$}

$$
\left.\left.\begin{array}{c}
\mathrm{B}_{3,1}=\left\{\begin{array}{l}
{\left[\begin{array}{l}
-(\Omega+1)^{2} e^{-M \phi-m\left(H_{f}-\phi\right)}+(\Omega-1)^{2} e^{-M \phi+m\left(H_{f}-\phi\right)}+\left(1-\Omega^{2}\right) e^{M\left(\zeta_{1}-\zeta_{2}\right)-m\left(H_{f}-\phi\right)}+ \\
\left(\Omega^{2}-1\right) e^{M\left(\zeta_{2}-\zeta_{1}\right)-m\left(H_{f}-\phi\right)}+\left(\Omega^{2}-1\right) e^{M\left(\zeta_{1}-\zeta_{2}\right)+m\left(H_{f}-\phi\right)}+\left(1-\Omega^{2}\right) e^{M\left(\zeta_{2}-\zeta_{1}\right)+m\left(H_{f}-\phi\right)}+ \\
(\Omega-1)^{2} e^{M \phi-m\left(H_{f}-\phi\right)}-(\Omega+1)^{2} e^{M \phi+m\left(H_{f}-\phi\right)}+8 \Omega
\end{array}\right]} \\
{\left[\begin{array}{l}
(\Omega+1)^{2} e^{-M \phi-m\left(H_{f}-\phi\right)}-(\Omega-1)^{2} e^{-M \phi+m\left(H_{f}-\phi\right)}-4 \Omega+\Omega^{2} e^{M\left(\zeta_{1}-\zeta_{2}\right)-m\left(H_{f}-\phi\right)}+ \\
e^{M\left(\zeta_{1}-\zeta_{2}\right)+m\left(H_{f}-\phi\right)}-\Omega^{2} e^{M\left(\zeta_{1}-\zeta_{2}\right)+m\left(H_{f}-\phi\right)}-e^{M\left(\zeta_{1}-\zeta_{2}\right)-m\left(H_{f}-\phi\right)}
\end{array}\right] e^{M \zeta_{2}}} \\
{\left[\begin{array}{l}
\left(\Omega^{2}-1\right) e^{M\left(\zeta_{2}-\zeta_{1}\right)-m\left(H_{f}-\phi\right)}+\left(1-\Omega^{2}\right) e^{M\left(\zeta_{2}-\zeta_{1}\right)+m\left(H_{f}-\phi\right)}+(\Omega-1)^{2} e^{M \phi-m\left(H_{f}-\phi\right)}- \\
(\Omega+1)^{2} e^{M \phi+m\left(H_{f}-\phi\right)}+4 \Omega
\end{array}\right] e^{-M \zeta_{2}}}
\end{array}\right]
\end{array}\right]\right\}
$$

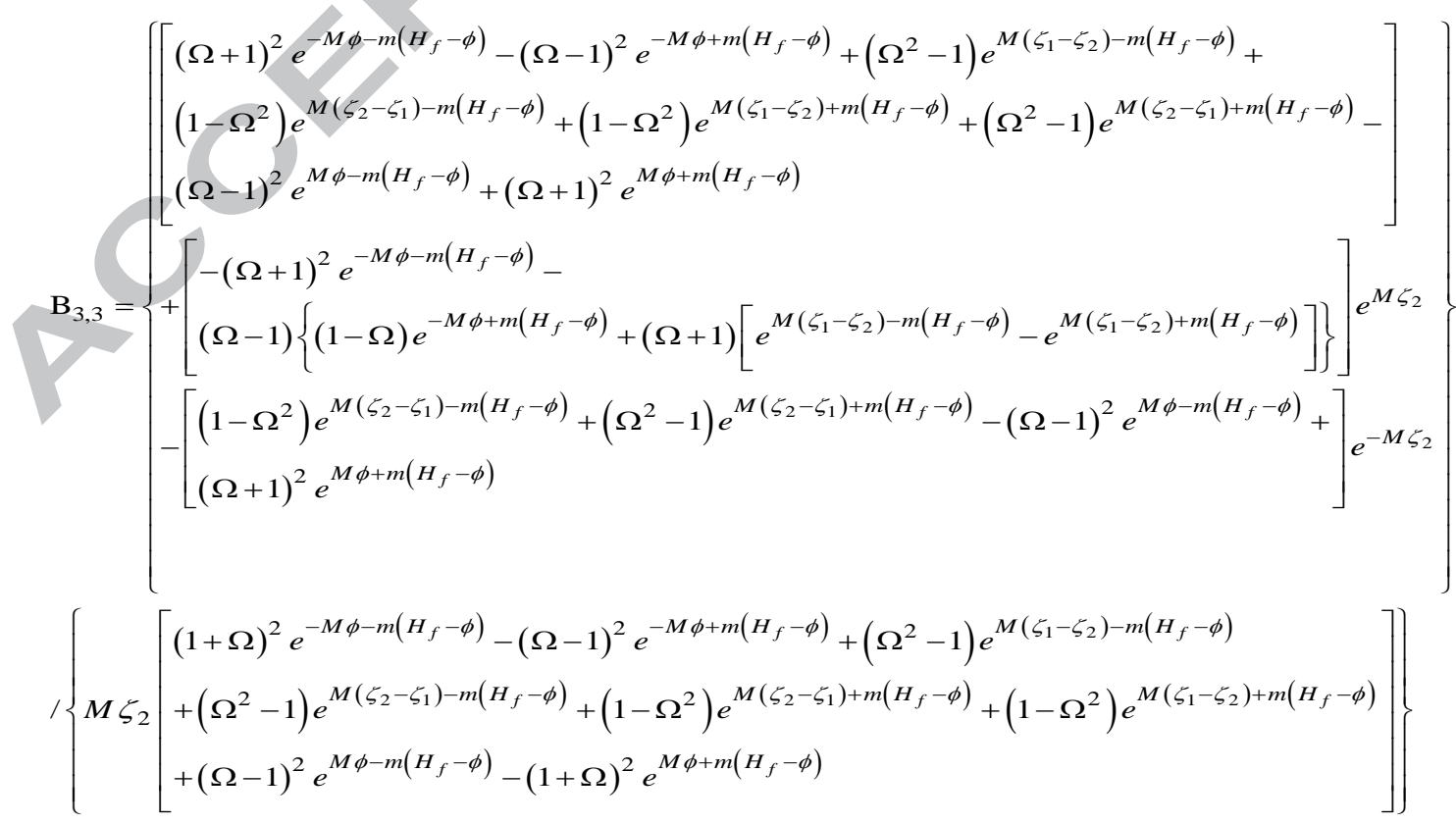




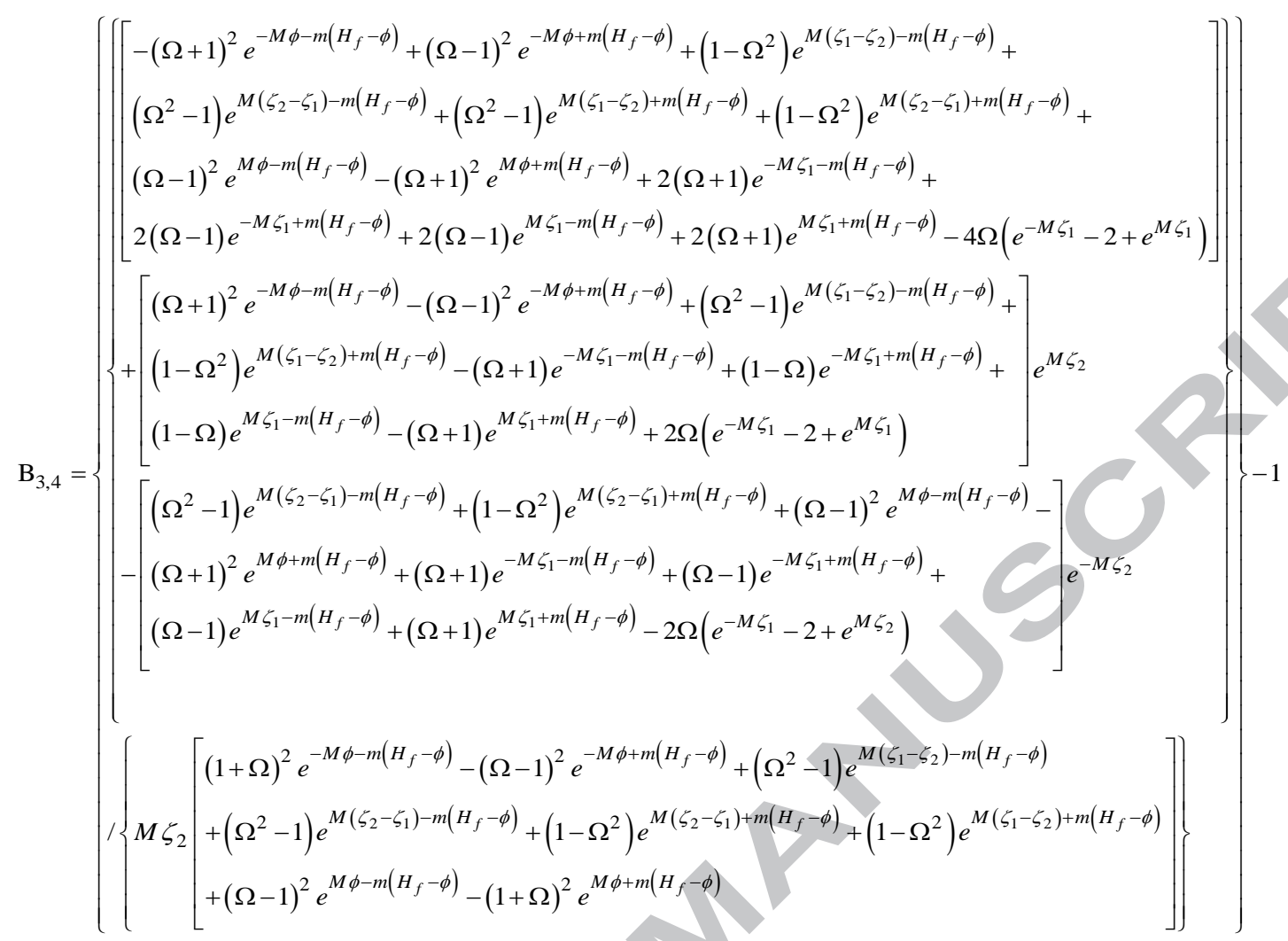

where

$M \quad$ is the wet fin parameter;

$m \quad$ is the dry fin parameter;

$\zeta_{1} \quad$ is the length of first fin portion fp1, measured from the fin base;

$\zeta_{2}$ is the length of third fin portion fp3, measured from the fin tip;

$\phi \quad=\zeta_{1}+\zeta_{2}$

$\Omega \quad=M / m ;$ and

$H_{f} \quad$ is the total fin height. 


\section{Highlights}

- A numerical model for wet fins of a minichannel evaporator is developed.

- Fin theory is adopted in conjunction with moving boundary technique.

- A comparative study between the proposed model and a 2D model is implemented.

- Both models predict similar temperature profiles and dehumidifying conditions.

- The current model saves computational cost up to $95 \%$ compared to the $2 \mathrm{D}$ model. 